\title{
Article
}

\section{Catalan as a Heritage Language in Germany}

\author{
Laia Arnaus Gil 1,*(D) and Amelia Jiménez-Gaspar ${ }^{2}$ (D) \\ 1 Department of Romance Linguistics, University of Wuppertal, 42119 Wuppertal, Germany \\ 2 Spanish, Modern and Classical Department, University of the Balearic Islands, 07122 Palma, Spain; \\ amelia.jimenez@uib.es \\ * Correspondence: arnaus@uni-wuppertal.de
}

check for updates

Citation: Arnaus Gil, Laia, and Amelia Jiménez-Gaspar. 2022. Catalan as a Heritage Language in Germany. Languages 7: 43. https:// doi.org/10.3390/languages7010043

Academic Editor: Tanja Kupisch

Received: 12 September 2021

Accepted: 10 February 2022

Published: 22 February 2022

Publisher's Note: MDPI stays neutral with regard to jurisdictional claims in published maps and institutional affiliations.

Copyright: (C) 2022 by the authors. Licensee MDPI, Basel, Switzerland. This article is an open access article distributed under the terms and conditions of the Creative Commons Attribution (CC BY) license (https:// creativecommons.org/licenses/by/ $4.0 /)$.

\begin{abstract}
Germany is currently the third country with more Catalan residents mainly characterized as families with children born in Germany but raised with Catalan as heritage language (HL). Only few studies have investigated Catalan as an HL in Germany. Our study tries to fill this gap with spontaneous recordings of 16 bilingual and trilingual children (mean age 5;7). In terms of language competence (measured via MLU), balanced bilingualism is present in most children (44\%), followed by those showing a dominance into German (38\%). Interestingly, regarding language use (measured in $\mathrm{w} /$ minute), both balanced and Catalan dominants were fluent in both L1s similarly, while the German dominant group mostly prefer German. Moreover, the parents filled in a questionnaire on current and cumulative input from which some factors were examined such as family language policies (FLP), child's language choice to the Catalan-speaking parent, Catalan skills of the non-native parent, family language and frequency of comprehension and production activities. In a nutshell, the results show that FLP and HL as FL or no FL seem to have an impact in the child's grammatical development in the very early years, as opposed to family language. Children mostly direct their speech in the HL when talking to the Catalan-speaking parent.
\end{abstract}

Keywords: heritage language; Catalan as a heritage language; early bi- and trilingualism; language competence; fluency; input quantity; input quality; family language policies

\section{Introduction}

Little is known about the Catalan-speaking community in Germany. According to the Statistic Centres of the three Catalan-speaking autonomous communities in Spain (IDESCAT 2020; IBESTAT 2020; PEGV 2020), Germany is the third country worldwide, after France and Argentina, to be chosen by Catalans from Catalan-speaking regions in Spain as their (new) country of residence. According to the Spanish National Institute of Statistics (INE), this community in Germany is composed predominantly of Catalan (young) adult speakers between 16 and 64 (around 28,000), followed by those under 16 (approx. 12,000). Of 43,000 Catalans living in Germany, the data indicate that Catalans under 16 were born in Germany to a large extent, and the remaining ones were born in a Spanish Catalan-speaking region and later on, still in childhood, moved to Germany. By contrast, the older group (16-64) can be considered first-generation adult immigrants from these regions in Spain (INE 2020, cf. Section 2). Young Catalan speakers (i.e., under 16) residing in Germany could, thus, be considered heritage language (HL) speakers, since, following Aalberse et al. (2019, p. 1), an HL speaker can be defined as a speaker who "learned a language at home that is not the dominant language of the country." This implies that in the early years, those speakers were either exposed exclusively to this (and maybe other) heritage language(s) at home, and later, i.e., in preschool or primary school, they had contact with the majority language $(\mathrm{MaL})$, or they received input in both the HL(s) and the MaL simultaneously at home.

Numerous studies have tried to identify several factors that promote linguistic competence in the HL. Some factors that have been examined and seem to contribute to 
HL-promotion are: the absence of the MaL at home, some family language policies (FLP), institutional support of the HL, the quantity of HL exposure, variety of contacts speaking the HL(s), the use of media in the HL, and language skills in the HL of the non-native speaking parent (De Houwer 2009; Unsworth 2013; Chevalier 2015; Arnaus Gil et al. 2020). Regarding input quantity, the studies of Gathercole (2007) and Pearson et al. (1997) found a significant correlation between the amount of input in the HL and age (but see Döpke 1992 for other results). Specifically, Pearson et al. (1997) observed that input quantity in the HL is more than relevant in the young years (i.e., at age 2; $0^{1}$, approximately) when it comes to vocabulary development, yet input quality in the HL seems to gain importance in older years, where morphosyntactic development is concerned, as the study of Gathercole (2007) shows. ${ }^{2}$ Interestingly, when taking grammatical development (measured via mean length of utterance or MLU) and age of acquisition (simultaneous vs. early bilinguals) into consideration, Thordardottir (2015), in her study on the acquisition of two majority languages, observed that they showed similar rates of language proficiency as their monolingual peers. This was the case as long as the amount of input and exposure were kept similar. What is clear is that a minimum amount of input is required for a child to be an active multilingual, that is, to use all L1s productively. For instance, Quay (2001) observes that in order for Freddy to use English with her father, 20\% of English input was enough.

FLPs have extensively emphasized the role of input for HL competence, with the focus on describing input consistency in speech directly addressed to the child, since this may promote output consistency (Chevalier 2015; Lanza 2004; Kasuya 1998). Chevalier (2015), Braun and Cline (2014), De Houwer (2004, 2007) and Hoffmann (1985) observed, however, that the choice of a certain FLP is not as important as keeping the MaL outside the home as much as possible, perhaps restricting its use as the language in family conversations. In this respect, it might be interesting to examine the role of the parent who is non-native in the HL when considering her/his L2 linguistic skills. The studies of De Houwer $(2004,2007)$ and Arnaus Gil et al. (2020) noticed that a child's HL competence is positively influenced by the $\mathrm{L} 2$ competence of the non-native parent; understanding the HL already seems to favour the child's linguistic competence in the HL. When it comes to qualitative factors that may contribute to HL promotion, the socio-economic status of the languages involved may be of importance. In this respect, although this factor has not been studied in the literature in depth yet, the work by Cobo-Lewis et al. (2002) detected that social class and economic status affected the acquisition of the MaL. Their role in preserving the HL was unfortunately less clear. The parental discourse style (e.g., persistence to use the HL, requests for translation, the use of repetitions, and the supply of vocabulary) may also have an effect on promoting language acquisition. In her study, Chevalier (2015) showed that the request for translation has an especially positive effect on active multilingualism.

Before starting preschool, it might be the case that children are at home with one of their parents who are enjoying maternity or paternity leave. This means that during the first months of the children's lives, one of the parents might have spent much more time with them. The recent study of Kozak et al. (2021) investigated the relationship between the cognitive and linguistic abilities of 446 children living in the US (mean age of 29.53 months) and the role of (i) working/not working mothers after birth as well as (ii) how the (un)paid leave of working mothers might affect those abilities. The authors used the Parent Report of Children's Abilitites-Revised (PARCA-R) in order to measure the non-verbal cognition (34 questions), vocabulary (with a list of 100 common words), and sentence complexity (12 questions). The last two categories were put together to assess the children's linguistic scores. The mothers of the 446 children were divided into four groups depending on variables (i) and (ii) previously mentioned: Group 1-not working; Group 2-stopped working after birth and did not return to their jobs; Group 3-took unpaid leave before starting to work again after birth; Group 4-took paid leave before starting to work again after birth. We will now focus on the results concerning the children's linguistic scores. First, the authors observed that mothers of groups 3 and 4 (i.e., those who started working after birth, after enjoying some maternity leave) had infants with significantly 
higher linguistic scores than mothers who did not work after birth (i.e., those belonging to groups 1 and 2). Importantly, these results were independent of family income. In other words, higher linguistic scores for working mothers were stated for both lower and higher income groups. Second, and focusing on mothers of groups 3 and 4 , the study further showed that those mothers who enjoyed paid maternity leave before starting to work after birth had toddlers with significantly higher linguistic scores than those mothers who had unpaid leave (i.e., those from group 3). These results were, again, independent of family income. Finally, the authors found no relationship between the length of (un)paid maternity leave and the children's linguistic scores. ${ }^{3}$ These results are significant for our study, since they indicate that maternity leave has a positive impact on children's linguistic development in the early years of life.

Our contribution to this special issue on HL in Germany is twofold. First, we want to describe the Catalan community in Germany, mainly focusing on the younger generation who acquire Catalan as an HL. Second, we present a preliminary study with sixteen children being raised with Catalan and German (and another L1) in the German city of Hamburg, and who have been exposed to Catalan from a native Catalan-speaking parent at home. Since the previous literature on the acquisition of Catalan as an HL in Germany is scarce (but cf. the works by Arnaus Gil et al. 2019; Arnaus Gil and Müller 2020), our study focuses mainly on questions related to language dominance, fluency and how some of the input factors described above might promote HL competence.

This paper is structured as follows. In section two, we describe the Catalan community outside Spanish regions where Catalan varieties enjoy a co-official status together with Spanish (Catalonia, Balearic Islands, and the Valencian Community). Section three presents empirical studies investigating the Catalan community in the diaspora, mainly under two different points of view. On the one hand, the works by Juarros-Daussà and her colleagues $(2012,2013,2015,2020)$ and the study by Peix (2013) focused on Catalan transmission in HL-contexts in the United States and France, respectively. On the other hand, the works by Arnaus Gil and colleagues emphasised the early acquisition of Catalan as an HL in Germany. Section four introduces our study on 16 bi- and trilingual children with Catalan as (one of their) L1(s) being raised in the German city of Hamburg, and section five presents the results. This paper concludes with a summary and discussion of the main results, as well as future investigations in section six.

\section{Catalan in the Diaspora}

Following the Statistic Centres of Catalonia (IDESCAT 2020), the Balearic Islands (IBESTAT 2020), and the Valencian Community (PEGV 2020), there are currently 353,493 people with one of these three origins living abroad (henceforth, Catalans). Over 50\% come from Catalonia, followed by those who lived in the Valencian Community (38\%) and the Balearic Islands $(10 \%)$. The country that accommodates most of the Catalans living abroad is France with 80,425, followed by Argentina $(55,605)$, Germany $(42,924)$, the United Kingdom $(40,325)$, and the United States $(19,006)$. The number of Catalans residing in Germany has increased almost $60 \%$ in the last eleven years (2009-2020), specifically, from 17,998 to around 43,000 in 2020 . Moreover, when considering the three age groups (i.e., under 16, 16-64, above 65), an equal distribution between male and female speakers is observed (cf. Figure 1): 
Men

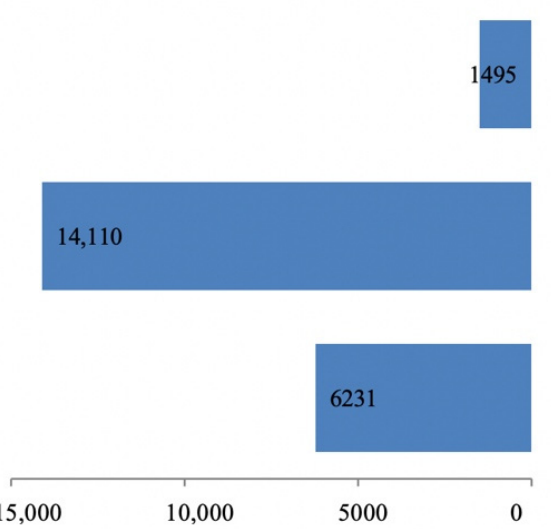

Women

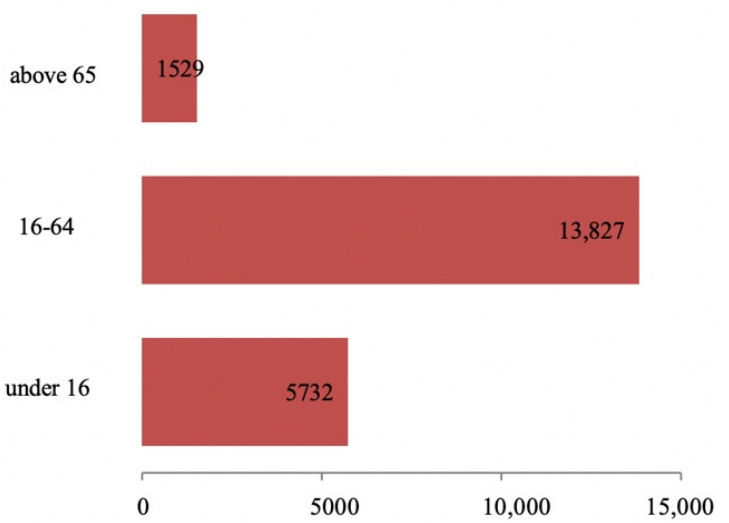

Figure 1. Catalans living in Germany according to age (INE 2020).

As seen in Figure 1, the majority is comprised in the 16-64 group, followed by those aged under 16. Interestingly, when considering the country of birth for the 43,000 registered Catalan speakers in Germany, approximately 9500 were born in Germany and are also registered in Catalonia or the Balearic Islands. This number is comparable to the population under 16 living in Germany who are registered in Catalonia or the Balearic Islands (8264 and 787, respectively, cf. INE 2020). ${ }^{4}$ From these data, we can cautiously assume that those registered as Catalans, aged above 16 and living in Germany are mainly first generation immigrants from the Catalan-speaking communities in Spain (i.e., 18,691, INE 2020) ${ }^{5}$, whereas children and teenagers aged under 16, from Figure 1, are generally born in Germany and have some Catalan bonds through family members with the Catalan-speaking regions in Spain (generally, with first-generation immigrants).

During the last years, this community of Catalans has been organised in different associations and cultural groups. These groups are partly promoted by the regional governments, and have an important role in connecting their members socially and culturally, and in helping freshly arrived Catalans to gain a foothold in Germany. The Register of Catalan Communities, made available by the Government of Catalonia (Generalitat de Catalunya GENCAT 2020), specifies eight cultural associations (founded between 1986 and 2014) with a total of 744 active members in the following cities, ordered according to their year of foundation: Essen, Kiel, Hamburg, Cologne, Munich, Berlin, Stuttgart, and Frankfurt. Moreover, two other associations should be added: one in Berlin and one in Mainz. The former is the Casa Balear de Berlin, founded in 1997, which developed into the association Amics de Mallorca, promoted by the Balearic Government (Buades Crespí et al. 2001). The Valencian Government founded the second association based at the University of Mainz. It offers a common space for students from the Valencian Community who want to start or continue their studies in Germany (SEACAVA, cf. CEVEX 2020).

\section{Previous Studies on Catalan in the Diaspora}

In this section, we present the few studies that have described the current situation of some Catalan communities in the diaspora. In particular, we are interested in families that include at least one Catalan-speaking parent. Section 3.1 presents those (socio)linguistic studies from Catalan families in the United States and France. Section 3.2 describes the studies focused on the early acquisition of Catalan as an HL in Germany.

\subsection{Studies on Catalan Families outside Catalan-Speaking Regions in Spain}

Most research investigating the Catalan community in the diaspora is centred on the works by Juarros-Daussà and her colleagues on Catalan families living in New York City (NYC). The quantitative study by Casesnoves-Ferrer and Juarros-Daussà (2015) explored 
the factors that favour the transmission of the HL Catalan within the family, with the aid of a questionnaire administered to 62 participants (mean age 39;0). Following the Spanish census numbers from 2011, the authors estimated that 1830 (with 322 Catalans under 18) were living in NYC (Casesnoves-Ferrer and Juarros-Daussà 2015, p. 465). The Catalan community in NYC is well organised and benefits from numerous political and non-governmental organisations that promote the Catalan language and culture. Most Catalans participating in this study had their origins in the Catalan-speaking regions of Spain (92\%) and had lived in the United States for at least three years. The questionnaire consisted of 68 questions with seven sections that tried to capture information on linguistic aspects; intergenerational transmission (i.e., linguistic uses at home); the use of languages in the media; Catalan, Spanish and American identity; and the participants' linguistic attitudes towards these three languages (cf. Casesnoves-Ferrer and Juarros-Daussà 2015 for an overview). As 33 of the 62 participants indicated that they had children, the authors examined these Catalans in detail. The authors concluded that the interplay among three variables accounts for $43 \%$ of the variance in the transmission of Catalan from parents to their children: they noticed that Catalan had a higher likelihood of being transmitted from one generation to the next one when the Catalan linguistic competence of the nativespeaker parent was high, when this parent had not been living in the US for so long, and when his/her linguistic values towards Spanish were kept low (Casesnoves-Ferrer and Juarros-Daussà 2015, p. 485).

Casesnoves-Ferrer and Juarros-Daussà (2012) and Juarros-Daussà $(2013,2020)$ took a more qualitative approach to the same Catalan community in NYC. ${ }^{6}$ Specifically, they were interested in the multilingual families' linguistic practices and ideologies to better understand which factors contributed to the family decision of transmitting Catalan to the next generation. The data were collected during informal interview settings between 2008 and 2018. Fifteen Catalan families with a total of 29 children participated in this study. ${ }^{7}$ All families belonged to the (upper)middle class, and all children had US nationality. Due to the possible family language constellations, English, as well as Spanish and Catalan, were considered for the analysis of linguistic transmission. Concerning English, the authors state that the transmission of English was ensured across families (i.e., English as a community language, and as part of the languages spoken at home, would be acquired with ease). As for Spanish and Catalan, they noticed that Catalan families prioritised Catalan transmission over Spanish, the former being passed over in almost $80 \%$ of the cases, and the latter only reaching 64\% (Juarros-Daussà 2013, p. 151). The linguistic goals for these families were straightforward: they wanted their children to become proficient in Catalan, yet only 13 of 20 Catalan parents indicated that they had such expectations for Spanish (Juarros-Daussà 2020). This observation is interesting if we consider that both Spanish and English were common languages within the family more frequently than Catalan and English. On a more qualitative level, the authors extracted some factors that would play a relevant role when transmitting Catalan, English, or Spanish to the next generation. For both English and Spanish, great importance was given to their instrumental (i.e., economic or practical) value in the community in which they were living. Nevertheless, when considering integrative and personal values, these seemed to be determinant factors for Catalan intergenerational transmission. In other words, "the role that the minority language [Catalan] has in the construction of identity, personal satisfaction, and the feeling of belonging to the group" was the most important factor for its transmission (Juarros-Daussà 2013, p. 151).

We want to conclude this section with a recent study of the Catalan community in France. As mentioned, France is the country that gathers the highest number of Catalans living abroad. However, we are only aware of Peix's (2013) work who examined the Catalan community in the so-called North of Catalonia, in the southern region of France, also called Rousillon. This region is composed of three districts (Perpignan, Prades and Ceret) that traditionally act as a unit of Catalan language and culture (Hawkey 2011). Historically, this region has been under French and Spanish control several times. With the Treaty of the Pyrenees in 1659, it became part of France, and French was the only language permitted. 
With the constitutional reform by the French Parliament in 2008, regional languages in France gained much importance. Since then, Catalan has begun to be taught in schools and to be integrated into bilingual education systems (Peix 2013). Peix's study examined the families' linguistic configurations, origins, and reasons for enrolling their children in a French-Catalan bilingual school. With the aid of a questionnaire sent to 19 schools across this territory during the school year 2009-2010, the author contacted 295 families with children in grade 5. She received a total of 141 filled questionnaires back, which represents a return rate of $48 \%$. Concerning information on FLP, around $71 \%$ of the families indicated that they used exclusively French at home. The remaining 29\% used French in conjunction with another language at home, mainly Catalan (10.90\%), and followed closely by Spanish (10.30\%). Regarding family origins, Peix's (2013) study gathered information from 168 parents. Half of the participants indicated that they had Catalan origins, almost $34 \%$ came from other regions in France, and 16\% from other countries. Peix (2013, p. 400f.) admits that the questionnaire did not specify whether this Catalan origin goes back to Catalan-speaking regions in Spain or the same Northern region of Catalonia at the other side of the Pyrenees. In any case, the author points at the general decision of the surveyed families to transmit Catalan to their children by means of enrolling them in bilingual French-Catalan classes. The motivations are diverse, but some similarities in the families' responses were identified. The main reason was to get to know and transmit Catalan language and culture to the next generation (Peix 2013, p. 402). Interestingly (but not surprisingly), as was the case for the Catalan families in NYC, the determinant factor for language transmission had to do with personal values and the will to pass on those aspects that made up a part of the family's identity, namely, the identification with (one of) the minority/heritage language(s) in a context where other language(s) have a strong presence in society.

\subsection{The Early Acquisition of Catalan as an $H L$}

To our knowledge, only a few studies have dealt with the acquisition of Catalan as an $\mathrm{HL}$ and focused on its acquisition in Germany. That is why those studies are presented in detail as follows.

Arnaus Gil et al. (2019) investigated the acquisition of Catalan, Spanish, French, and German in a broad cross-sectional study with bi-, tri- and multilinguals (mean age 4;9) in Germany and Spain. Catalan, Spanish, and German were analysed in terms of majority and heritage languages, whereas French was only attested as an HL in two different linguistic environments (Germany and Spain). When it comes to the analysis of Catalan as an HL, this study presents valuable results on four young Catalan HL speakers (mean age 5;0) living in the German cities of Berlin and Hamburg with the language combination of Catalan-Spanish-German(-French). These young multilinguals were compared in different ways with their twelve multilingual peers (mean age 5;6) living in Palma de Mallorca (Balearic Islands, Spain), where Catalan has a co-official status with Spanish. The receptive vocabulary in Catalan was assessed via the standardised Peabody Picture Vocabulary Test (PPVT), adapted from the French Peabody Version (Dunn et al. 1993). The results for the group growing up in Germany and for the group living in Palma de Mallorca showed statistical differences between them (Arnaus Gil and Müller 2020, p. 22), although the age-matched scores (i.e., those vocabulary scores according to children's age) in both environments (Germany and Palma de Mallorca) were very close to each other. ${ }^{8}$ According to the authors, although children obtained similar age-matched scores in the PPVT, the statistical differences in (receptive) language competence can be explained in terms of quantitative and/or qualitative input differences between the two groups, but not by the community language per se. Moreover, in terms of language dominance, three out of four children living in Germany with Catalan as an HL showed a balanced competence of Catalan with at least one of their other L1s, which could be one of the child's other HLs or German, the MaL (Arnaus Gil et al. 2019). 


\section{The Study}

\subsection{Participants}

We conducted a study with 16 Catalan-German simultaneous bi-/trilingual children, aged between 2;6 to 13;0 (mean age: 5;7). All children were born in Hamburg, except for two children (one child was born in Essen (Nordrhein-Westfalia, Germany) and one in Barcelona (Catalonia, Spain). They all received Catalan input from (at least) one of their parents, who was native in this language. Likewise, 12 of them also received German input at home, and the rest were exposed to German at school or in kindergarten. Interestingly, no family included Spanish as a language in the family, although all Catalan-speaking parents indicated that they were proficient (and somewhat bilingual) in this language. All families were composed of one Catalan-speaking parent and one non-native Catalan-speaking parent, except for two children, Duna and Alba (see Table 1). All families belonged to the (upper)middle class, which was determined by parental education. Table 1 summarises the information of each child according to age and L1s $\left(\mathrm{L}_{\mathrm{A}}, \mathrm{L}_{\mathrm{B}}\right.$ and $\left.\mathrm{L}_{\mathrm{C}}\right)$ and presents information on sibling pairs and the languages spoken by the parents to the children in the last column.

Table 1. Children according to age, L1s and information on sibling pairs.

\begin{tabular}{ccccccc}
\hline Child & Age & $\mathbf{L}_{\mathbf{A}}$ & $\mathbf{L}_{\mathbf{B}}$ & $\mathbf{L}_{\mathbf{C}}$ & Information on Sibling Pairs & Parents' Languages \\
\hline Lena & $2 ; 8,10$ & Catalan & German & & & Ger-Cat \\
Kenya & $2 ; 11,21$ & Catalan & German & & Sibling pair 1 & Ger-Cat \\
Duna & $3 ; 11,25$ & Catalan & German & & Catalan \\
Nil & $4 ; 3,11$ & Catalan & German & English & Sibling pair 2 & Ger-Cat \\
Pau & $4 ; 3,22$ & Catalan & German & Thai & & Cat-Thai \\
Magalí & $4 ; 10,23$ & Catalan & German & & & Ger-Cat \\
Emily & $5 ; 1,16$ & Catalan & German & English & Ger-Cat \\
Jan & $5 ; 2,25$ & Catalan & German & & Sibling pair 3 & Ger-Cat \\
David & $5 ; 8,18$ & Catalan & German & & & Ger-Cat \\
Júlia S. & $5 ; 9,16$ & Catalan & German & & & Ger-Cat \\
Mila B. & $5 ; 9,10$ & Catalan & German & English & Sibling pair 2 & Ger-Cat \\
Dana & $5 ; 10,22$ & Catalan & German & & Sibling pair 1 & Ger-Cat \\
Julia K. & $7 ; 7,15$ & Catalan & German & & Sibling pair 3 & Ger-Cat \\
Alba & $10 ; 6,22$ & Catalan & German & & Sibling pair 1 & Catalan \\
Mila P. & $11 ; 2,18$ & Catalan & German & & Sibling pair 1 & Ger-Cat \\
Nina & $13 ; 3,22$ & Catalan & German & & & Ger-Cat \\
\hline
\end{tabular}

\subsection{Methodology}

We analysed spontaneous synchronic data from video-taped recordings in a game situation in each of the children's L1s (monolingual mode, Grosjean 2001) that lasted approximately $30 \mathrm{~min}$ for each L1. The structure of the conversation was adapted according to the child's age. Specifically, with younger children (from 2;5 to 7-8 years), it was accommodated with respect to the children's motivation and interest at the moment of the recording, so that the game situation elicited as much spontaneous language as possible. For instance, researchers proposed playing the following games: Story Cubes to create stories, and Guess Who and Dobble to find differences across targets with the same images. The recording situations with older children (from 7 to 14 years, approximately) were mostly based on semi-guided interviews focusing on specific topics, such as series and movies that children were currently watching, and holidays. In that regard, older children talked about determined episodes of their favourite series and about some of the characters' actions, as well as about their last holidays. ${ }^{9}$ Children were engaged in conversations with two different persons, one German-speaking and one Catalan-speaking adult. ${ }^{10}$ Regarding the order of the recordings, researchers decided to begin with the language children felt more comfortable with at that moment, in order to create a relaxed environment in which the children would be willing to speak and interact in the target language. The sessions 
took place mainly at the children's homes, and parents were not present in the room during the recordings.

Once each child was recorded in his/her L1, Catalan and German native speakers were engaged to transcribe them and to calculate MLU and fluency values (cf. Section 5.1). Transcriptions, as well as MLU and fluency values, were double-checked by other native speakers of Catalan and German. ${ }^{11}$

In addition, parents completed a questionnaire about current and cumulative input based on the works by Unsworth (2013) and Torregrossa and Bongartz (2018). The questionnaire presents 11 sections (explained in Table 2) based on input quantity and quality factors in the children's different L1s.

Table 2. Sections and their focus from the parental questionnaire.

\begin{tabular}{|c|c|c|}
\hline \multicolumn{2}{|r|}{ Section } & \multirow{2}{*}{$\begin{array}{c}\text { Focus } \\
\begin{array}{l}\text { Personal information such as name, date of birth, } \\
\text { gender, place of birth and residence. }\end{array}\end{array}$} \\
\hline A & $\begin{array}{l}\text { Children's general } \\
\text { information }\end{array}$ & \\
\hline B & $\begin{array}{l}\text { Information on the children's } \\
\text { linguistic environment }\end{array}$ & $\begin{array}{l}\text { Personal information about parents and the } \\
\text { languages used in the child's environment. }\end{array}$ \\
\hline $\mathrm{C}$ & Language fluency & $\begin{array}{l}\text { Languages the child is exposed to, and speaks, } \\
\text { with the different people with whom (s)he } \\
\text { spends time, and how often. }\end{array}$ \\
\hline $\mathrm{D}$ & Literacy $(<6 ; 0)$ & \multirow{2}{*}{$\begin{array}{l}\text { Frequency of different comprehension and } \\
\text { production activities in the different L1s of the } \\
\text { child, depending on his/her age (younger or } \\
\text { older than } 6 \text { years of age). }\end{array}$} \\
\hline E & Literacy $(>6 ; 0)$ & \\
\hline $\mathrm{F}$ & Linguistic domains $(>6 ; 0)$ & $\begin{array}{c}\text { Frequency of use of children's L1s in specific } \\
\text { linguistic domains, such as writing an email } \\
\text { or a letter. }\end{array}$ \\
\hline G & Cumulative input & $\begin{array}{l}\text { Frequency of use of children's L1s during the } \\
\text { different stages of their life (preschool, primary } \\
\text { and secondary school). }\end{array}$ \\
\hline $\mathrm{H}$ & $\begin{array}{l}\text { Family linguistic } \\
\text { competencies }\end{array}$ & $\begin{array}{c}\text { Linguistic competencies in the different skills } \\
\text { (understanding, speaking, writing, and reading) } \\
\text { of parents and siblings in German, Catalan, } \\
\text { and Spanish. }\end{array}$ \\
\hline I & $\begin{array}{l}\text { Children's assessments about } \\
\text { his/her linguistic } \\
\text { competencies in his/her } \\
\text { different L1s }\end{array}$ & $\begin{array}{l}\text { Linguistic competencies in the different skills } \\
\text { (understanding, speaking, writing, and reading) } \\
\text { of children in German, Catalan, and Spanish, as } \\
\text { well as their attitudes towards the different } \\
\text { languages they use. }\end{array}$ \\
\hline $\mathrm{J}$ & $\begin{array}{c}\text { Travelling (to } \\
\text { Catalan-speaking regions) }\end{array}$ & $\begin{array}{l}\text { Frequency and languages used in } \\
\text { Catalan-speaking regions per year. }\end{array}$ \\
\hline K & $\begin{array}{l}\text { Family (including the child) } \\
\text { assessments about } \\
\text { bilingualism/multilingualism }\end{array}$ & $\begin{array}{l}\text { Assessments about the importance of } \\
\text { understanding, speaking, writing, and reading } \\
\text { Catalan, German, and Spanish. }\end{array}$ \\
\hline
\end{tabular}

Each section presents specific questions, generally with the aid of Likert scales that allow us to analyse the different input quantity and quality factors. Table 3 presents the different input factors considered in the 11 sections of the parental questionnaire: 
Table 3. Input quantity and quality factors from the parental questionnaire ${ }^{12}$.

\begin{tabular}{cc}
\hline Input Quantity Factors & Input Quality Factors \\
\hline Amount of input & Family's linguistic competencies \\
Cumulative input & Cultural contact \\
Family language policies (FLP) & Language fluency (ling. domains) \\
Language constellation & $\begin{array}{c}\text { amount of family support towards } \\
\text { bilingualism/multilingualism }\end{array}$ \\
\hline
\end{tabular}

\subsection{Research Questions and Hypotheses}

Spontaneous data were examined to determine the children's language dominance and language fluency (see Section 5.1). Likewise, child-external factors from the input questionnaire were analysed and correlated with the children's language dominance and language fluency, to examine whether they play an important role in early language development (see Section 5.2). Specifically, we aim to answer the following research questions (RQ) and, following the literature, we formulate the resulting hypotheses $(\mathrm{H})$ :

(1) RQ1: Does input consistency relate to output consistency in child-parent-interactions?

Hypothesis 1 (H1). If parents choose to be consistent in their speech directed to children (i.e., only Catalan/only German), bi- and multilingual children will mainly utter monolingual productions in their speech directed to the Catalan-speaking and the German-speaking parent.

(2) RQ2: Do the Catalan language skills of the non-native-Catalan-speaking parent positively promote HL competence or HL fluency?

Hypothesis 2 (H2). If the non-native-Catalan-speaking parent shows good language skills in this language, children might have the possibility to also interact in the HL with non-nativeCatalan-speaking parents and, therefore, this might positively influence the children's HL competence.

(3) RQ3: Does input quantity in the child's first early years have a substantial impact on HL acquisition?

Hypothesis 3 (H3). If input quantity in the child's early years positively influences $H L$ acquisition, children who spent substantially more time with the Catalan native parent (i.e., in terms of maternity/paternity leave) may show a better linguistic competence in the HL. ${ }^{13}$

(4) RQ4: Do comprehension and production activities in the HL promote a balanced competence between German and Catalan?

Hypothesis 4 (H4). If the frequency in HL activities has a positive impact on HL competence, children with greater exposure to these activities in the HL should show an even competence between the heritage and the majority languages.

(5) RQ5: If a family decides to exclusively use one language when all family members are present (family language) and irrespective of the family's FLP chosen, does this decision influence the child's language acquisition of the HL and the MaL?

Hypothesis 5 (H5). If a family chooses the HL as family language, this should positively influence HL acquisition.

In what follows, section five will present the results of our study. To begin with, Section 5.1 will explore the linguistic competence of the bi-/trilingual children in their HL Catalan and the MaL German. 


\section{Results}

\subsection{Language Dominance and Language Fluency}

Several tools have been put forward in the literature to capture the child's linguistic competence in their respective L1s (cf. Müller et al. 2007, for an overview). One linguistic measure that has been widely used is MLU (Mean Length of Utterance), due to its objective and independent character, to assess children's language development and proficiency. ${ }^{14}$ As Schmeißer et al. (2016, p. 38) point out, language dominance could be defined as "the difference in proficiency in a bilingual's two languages". Therefore, MLU could be assumed to be a quantitative measurement that tries to capture the child's linguistic development qualitatively. The MLU-difference between the child's L1s will thus contribute to determine language dominance or balance. In order to calculate the MLU values of the child's L1s, some well-known strategies to balance cross-linguistic differences were taken into consideration (Müller et al. 2007). The decision to use MLU as a measurement for language competence was made considering the type of explorative study for Catalan as an HL in Germany, in which spontaneous familiar conversations in all the child's L1s were carried out (cf. Section 4.2).

The following Figure 2 shows the MLU-values for Catalan (solid line) and German (dotted line) in the columns, as well as the standard deviation values (SD) as lines for each MLU value for each child, ranked on the x-axis according to age.

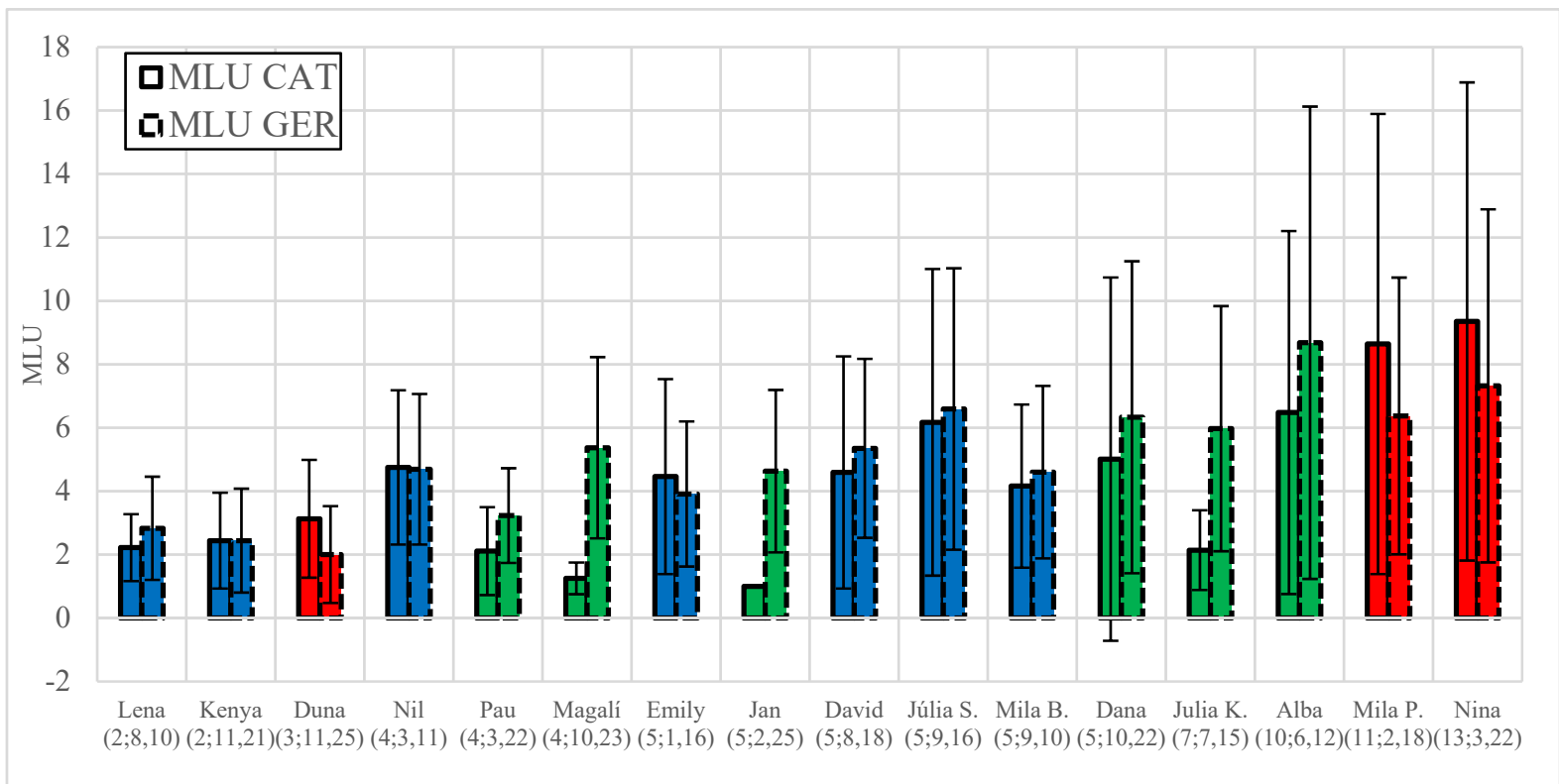

Figure 2. MLU values for Catalan (solid line) and German (dotted line), and language dominance (blue = balanced; green = German dominant; red = Catalan dominant) for the sixteen bi- and trilinguals according to age.

The MLU values for both Catalan and German show an increasing tendency the older the children are. ${ }^{15}$ SD values illustrated on each of the children's MLU-columns show how variable children's sentences are according to length. Low SD values for MLU values, as the ones we observe for the younger children, reflect the actual sentence length of all utterances produced in a recording. Higher SD values, however, reveal greater variability in sentence length. From the figure above, we observe higher SD values, the older the children are, showing convergence to adult pragmatic discourse competencies (Arencibia Guerra 2008; Müller et al. 2007; Cantone et al. 2008). According to age, this increase in the SD values for both Catalan and German is statistically significant (for Catalan: $\mathrm{r}=0.78, p<0.05$; for German: $r=0.81, p<0.05)$. 
Following the works by Arencibia Guerra (2008), Hager (2014) and Patuto et al. (2014) among others, we classified the children according to their language dominance/balance with the aid of the difference between the MLU values of their L1s: 0-0.9 = balanced; $> \pm 1.0=$ dominant (negative value: Catalan dominant; positive value: German dominant). Figure 2 above presents the language dominance/balance according to the difference in the MLU values for German and Catalan: blue represents those children who showed a balanced behaviour between both L1s, green represents dominance towards German, and red represents dominance towards Catalan. In this sense, balanced bilingualism could be attested by seven children $(43.75 \%)$, followed by a similar number of children with a dominance towards German (37.5\%). Catalan-dominant children represent the smallest group $(18.75 \%)$. Interestingly, two out of three Catalan dominants are the oldest bilinguals of the sample, and are also siblings. If we look closer at the SD values for HL Catalan and for the MaL in Figure 2 and relate them to the child's language dominance, some interesting remarks can be made. First, taking the Catalan SD values, we observe that they are low for the balanced (blue) and the German-dominant (green) groups, as opposed to those children who are Catalan dominant, who show higher SD-values. Yet, the difference between both groups (i.e., balanced and German dominant vs. Catalan dominant) is not significant $(t(12)=-1.54, p>0.05)$. Second, if we consider children's SD values in German, Germanbut also Catalan-dominant children show higher SD values than the balanced group, which approached significance to a significant level $(t(12)=1.72, p=0.0554)$. Finally, focusing on the SD values for Catalan and German of the balanced children, it is interesting to note that $\mathrm{SD}$ values remain low (2.73 and 2.56, respectively), unlike the dominant language for the two dominant groups. This seems to indicate that balanced children show less variability, and thus, are more "conservative" in their productions. Put differently, they do not take the risk of using partly longer and partly shorter sentences, something that the dominant groups do in their respective dominant language. This difference between the balanced and the two dominant groups is statistically significant $(t(12)=-10.86, p<0.05)$.

Linguistic development can not only be described in terms of competence criteria, but also in terms of language use in the child's L1s. In this respect, we are interested in the automatism, i.e., in the more-or-less quick access to the child's L1s when speaking (Müller et al. 2007; Arencibia Guerra 2008; Hager 2014). Some quantitative tools have been proposed in the literature in order to capture the child's language use in each of his/her L1s, such as fluency (measured in words per minute, cf. Arencibia Guerra 2008) or the percentage of utterances addressed to each parent in the (non-)appropriate language (Döpke 2000). Fluency has been used in previous literature as a criterion for language dominance as well (Müller and Kupisch 2003; Cantone et al. 2008), since the more-developed language is generally the one which is used the most (Arencibia Guerra 2008). Figure 3 presents the results for language fluency in all sixteen children, measured in words per minute, for both Catalan (solid line) and German (dotted line) as well as their respective SD values. The children are again ranked on the $\mathrm{x}$-axis according to age. Words per minute were calculated by counting all words in the language of the recording (i.e., all Catalan words in the Catalan recording, all German words in the German recording), and divided taking the length in minutes of the recording into consideration (cf. Arencibia Guerra 2008 for a detailed description).

As can be observed in Figure 3, older children display higher fluency in Catalan (the $\mathrm{HL}$ ) and German (the MaL) than younger children (for Catalan: $\mathrm{r}=0.8057, p<0.05$; for German: $r=0.8214, p<0.001)$. The yellow dots for each child represent the difference in fluency (FluencyD) between Catalan and German. Arencibia Guerra (2008, p. 127) arbitrarily set the difference of 11.99 words per minute as the boundary between those children who had a similar language fluency ( $<11.99$ words) and those who showed a higher language fluency for one of their L1s. This boundary is shown in Figure 3, with the yellow arrow in the y-axis on the $12 \mathrm{w} / \mathrm{min}$ mark. Moreover, nine children $(56.25 \%)$, represented with the blue columns, found themselves under the 11.99-word-level, which indicates that they had a similar language fluency in both of their L1s. By contrast, seven 
children showed a higher language fluency towards one of the two languages. Specifically, five children $(31.25 \%$ ) displayed higher rates in the MaL German (illustrated with the green columns) and two childred (12.5\%) exhibited higher fluency values for the HL Catalan (red columns). ${ }^{16}$

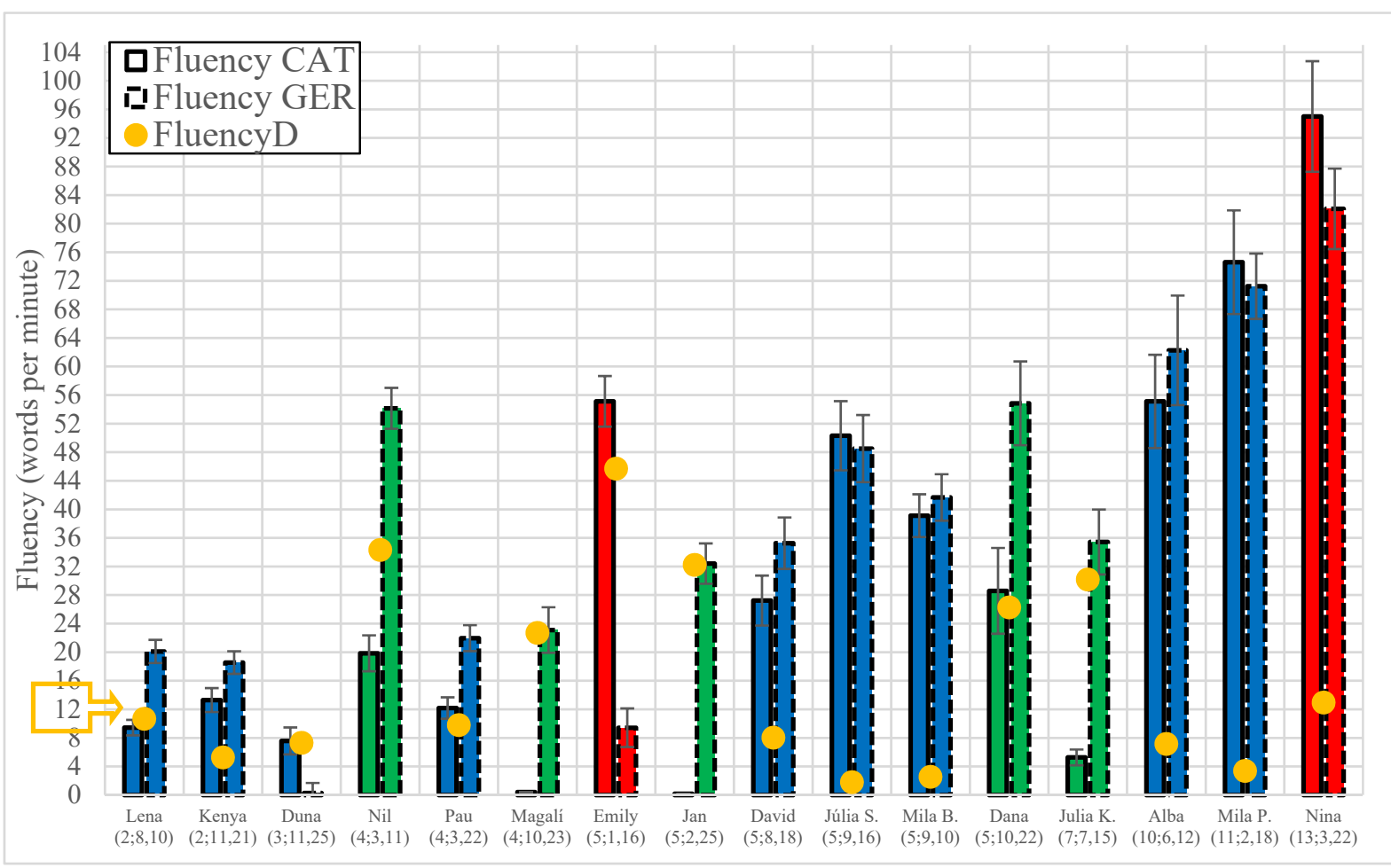

Figure 3. Fluency values for Catalan (solid line) and German (dotted line), as well as language fluency (blue = balanced fluency; green = higher German fluency; red = higher Catalan fluency) for the sixteen bi- and trilinguals according to age.

Now, let us compare the two figures we presented in this section that show linguistic measurements for language competence and language fluency. By comparing these data, we can ascertain whether the dominant group also uses a certain language more frequently, while the balanced children use their L1s in a similar way. The following Table 4 summarises this information and presents the number of children according to each category:

Table 4. Children's classification according to language dominance (MLUD) and language use (FluencyD).

\begin{tabular}{ccccc}
\hline & $\begin{array}{c}\text { Similar Language } \\
\text { Fluency for Both L1s }\end{array}$ & $\begin{array}{c}\text { Higher Language } \\
\text { Fluency for German }\end{array}$ & $\begin{array}{c}\text { Higher Language } \\
\text { Fluency for Catalan }\end{array}$ & $\begin{array}{c}\text { TOTAL } \\
\text { Balanced }\end{array}$ \\
\hline German dominant & 2 & 1 & 1 & 7 \\
\hline Catalan dominant & $3^{17}$ & 4 & 0 & 6 \\
\hline TOTAL & 10 & 5 & 1 & 3 \\
\hline
\end{tabular}

The relationship between language dominance and language fluency shows some interesting patterns. First, language dominance is distributed similarly across the balanced and the German-dominant group, whereas the category 'similar language fluency for both L1s' brings together approximately two thirds of the total number of children. Second, by looking at the relationships between language dominance and language fluency, the 
balanced group is clearly grouped as having a similar language fluency for both L1s, and two thirds of the German-dominant children can be classified as using this language the most. Finally, following the observations for the latter, we would expect to find a similar tendency for the Catalan-dominant group. However, we detect a similar fluency in both L1s for this group. Thus, our results seem to highlight that the children classified as fluent in both heritage and majority languages are, in turn, balanced or dominant in the HL in terms of language competence. By contrast, those who appeared to have a higher fluency in German are also more competent in the MaL.

In order to assess the factors that might influence children's language competence (in HL Catalan), we analysed child-external factors from the parental questionnaire on current and cumulative input related to language dominance. The results are reported in the following section.

\subsection{Child-External Factors and Language Dominance}

Several external factors were examined throughout the input questionnaire to verify whether they can influence children's language dominance. First, the FLP chosen by the family was examined, given that it allows us to analyse input consistency in the heritage and majority languages. Second, we considered an essential qualitative factor in parentchild communication, namely which language the child speaks to his/her Catalan-speaking parent. Focusing on the parents, we were also interested in assessing the Catalan skills of the non-native-Catalan-speaking parent to see whether the potential interaction between this parent and the multilingual child would positively influence the child's language competence in the HL. Additional factors linked to input quantity, such as the frequency of comprehension and production activities, might also be relevant. Finally, we also considered information on the children's first year of life. Particularly, we were interested in examining the impact on Catalan during this period, if the Catalan-speaking parent spent most of this time on maternity/paternity leave. ${ }^{18}$

Following Ronjat (1913) and Döpke (1988, 1992), the parental linguistic strategies in the familiar environment are decisive in the development of the children's different L1s, mainly in the case of the minority language and, in this case, the HL. In addition, as Juan-Garau and Pérez-Vidal (2001) argue, the consistency in applying the family language strategies (i.e., Family Language Policies, FLP) varies across families and, therefore, the results might also be different in terms of language dominance and fluency. As described in Section 1, the impact of maternity leave on the linguistic development of children might be relevant as well (Kozak et al. 2021). In a nutshell, the results show that those mothers who enjoyed maternity leave after birth had toddlers with higher linguistic scores (measured in vocabulary and sentence complexity) during childhood than those who did not. Thus, in this sense, we hypothesize, for the children's L1s in our study, that those children with parents who enjoyed maternity/paternity leave benefit from a higher amount of input in the parent's language; therefore, they should exhibit a higher competence in the language of the parent on maternity/paternity leave.

\subsubsection{Family Language Policies (FLP)}

FLP or family language strategies (Arnaus Gil et al. 2020) try to capture the consistency in which both the heritage and the majority language are displayed within and outside the family. The children of this study present four different family language strategies (LS), adapted from Arnaus Gil et al. (2020, p. 3), as can be seen in Table 5 below: 
Table 5. Family language strategies (adapted from Arnaus Gil et al. 2020, p. 3).

LS 1: 'one person-one language'(OPOL) with home support of the majority language

LS 2: OPOL with an extra majority language outside home

LS 3: one language-one environment

LS 4: bilingual parents with mixed languages

LS 1 can be considered a bilingual strategy (each parent speaks one language with the child and one language is, at the same time, the majority language). This strategy is used, for example, by the families of Lena, Jan, and Julia K. LS 2 is a trilingual strategy that entails the acquisition of $\mathrm{L}_{\mathrm{A}}$ and $\mathrm{L}_{\mathrm{B}}$ at home and an $\mathrm{L}_{\mathrm{C}}$ outside the familiar scope, i.e., the majority language German. For instance, Pau receives Catalan from his Catalan-native father and Thai from his Thai-speaking mother at home, and he is exposed to German in preschool. LS 3 corresponds to one of Romaine's (1995) six parental linguistic strategies 'one person-one language' and can be also considered a bilingual strategy: Both parents speak the same language, which is not the majority language, to the child. The child receives exposure to the majority language outside the home. The bilingual children, Alba and Duna, are being raised with this strategy. Finally, LS 4 is also a trilingual strategy, but the difference with LS 2 resides in the presence of three L1s at home: two languages from each parent (or both) and a third one via a prior conveyed family language. For instance, Nil and Mila B. are exposed to Catalan from their mother and German from their father. Both parents speak English to each other and report that they also use English with their children.

If we consider language dominance and the family choice concerning LS, we can observe that the LS has an impact on the children's language dominance (see Figure 4).

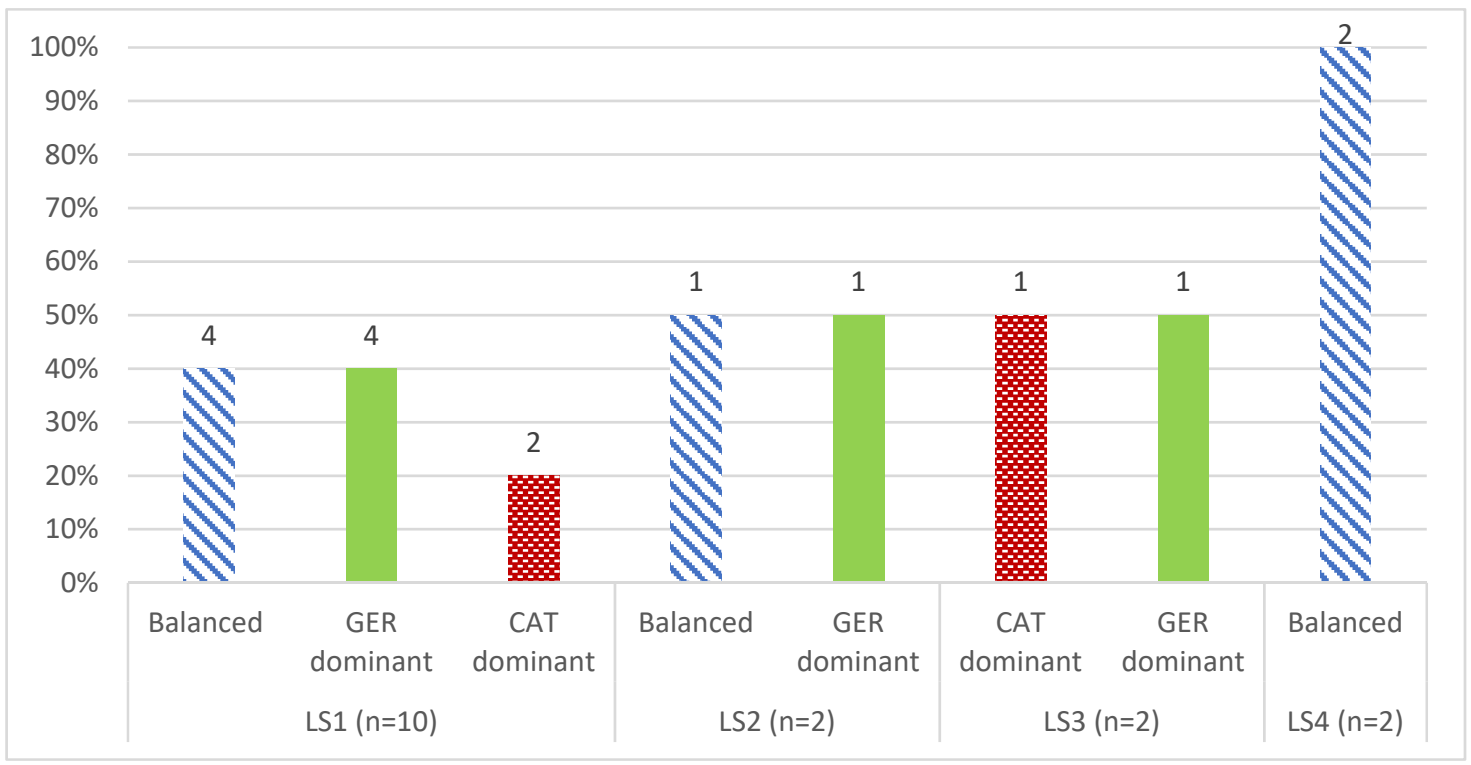

Figure 4. Classification of children according to LS and their dominance.

Figure 4 exhibits that 10 out of 16 children (62.5\%) follow LS1, while the other strategies show two children each. Regarding the group of families that follow LS1, we can classify the children according to their language dominance: four children (Lena, Kenya, David and Júlia S.) are balanced, while four are German dominant (Magalí, Dana, Jan and Júlia K.) and two are Catalan dominant (Mila P. and Nina). In other words, in $60 \%$ of the families that have chosen OPOL (LS1), children are either balanced or dominant in the HL. In the remaining $40 \%$, children are dominant in the MaL German. Considering the LS2, there are only two children (Pau and Emily) who acquire two HLs at home and the third language, German, outside the family scope. As we know, there is a difference between their language 
dominance, when two of their three L1s (Catalan and German) are only considered. Pau is German dominant, but Emily is balanced. Finally, notice that Pau has a similar fluency in Catalan and German, whereas Emily shows a higher fluency in the MaL (and a lower fluency in Catalan). To know whether LS2 is relevant for language dominance, the MLU values for Thai and English, respectively, should be considered. The families of Duna and Alba follow the third LS that consists of acquiring one HL at home, in this case, Catalan, while the MaL is acquired outside home. As is the case with the children in the LS2 group, two different outcomes with respect to language dominance are observed: Duna is Catalan dominant and Alba is German dominant. As in the case of Pau, both children have a similar fluency in their two L1s. Finally, the siblings Nil and Mila B. follow LS4 and have been classified as balanced in terms of language dominance: while they receive Catalan input from their mother, they also receive German from their father. In addition, their parents also speak English with them.

Following the four language strategies described in Table 5 above, we can examine how the children's exposure to their L1s is conveyed from the parental point of view. Nevertheless, it may be relevant to examine whether establishing a family language has an impact on children's mastering of their L1s. Specifically, if (one of) the HLs fulfills this role, this might positively influence the children's competence in this HL. This will be discussed in the following section.

\subsubsection{Family Language}

An additional relevant factor to our analysis is family language. According to the parental input questionnaire, family language is the language used when all family members are present. If no family language has been chosen, this indicates that the family uses all languages available in these situations. Table 6 provides information on the family language of each child compared to the LS used at home and the corresponding children's language dominance.

Table 6. Family language across LS and language dominance.

\begin{tabular}{|c|c|c|c|}
\hline Family Language & $\begin{array}{c}\text { Family Language } \\
\text { Strategy }\end{array}$ & Children & $\begin{array}{c}\text { Language } \\
\text { Dominance }\end{array}$ \\
\hline \multirow{4}{*}{ None } & \multirow{3}{*}{$\begin{array}{c}\mathrm{LS} 1: \mathrm{OPOL}+ \\
\text { support of } \mathrm{MaL}\end{array}$} & $\begin{array}{c}\text { Kenya P. }(2 ; 11) \\
\text { David }(5 ; 8) \\
\text { Júlia S. }(5 ; 9)\end{array}$ & Balanced \\
\hline & & Dana P. $(5 ; 10)$ & German dominant \\
\hline & & $\begin{array}{l}\text { Mila P. }(11 ; 2) \\
\text { Nina P. }(13 ; 3)\end{array}$ & Catalan dominant \\
\hline & $\begin{array}{l}\text { LS 2: OPOL + MaL } \\
\text { outside home }\end{array}$ & Pau $(4 ; 3)$ & German dominant \\
\hline \multirow[b]{2}{*}{ German } & \multirow[b]{2}{*}{$\begin{array}{c}\text { LS 1: OPOL + } \\
\text { support of MaL }\end{array}$} & Lena $(2 ; 8)$ & Balanced \\
\hline & & $\begin{array}{c}\text { Magalí }(4 ; 10) \\
\text { Jan K. }(5 ; 2) \\
\text { Júlia K. }(7 ; 7)\end{array}$ & German dominant \\
\hline \multirow[b]{2}{*}{ English } & $\begin{array}{l}\text { LS 2: OPOL + MaL } \\
\text { outside home }\end{array}$ & Emily $(5 ; 1)$ & \multirow[b]{2}{*}{ Balanced } \\
\hline & $\begin{array}{l}\text { LS 4: bilingual } \\
\text { parents with mixed } \\
\text { languages }\end{array}$ & $\begin{array}{l}\text { Nil B. }(4 ; 3) \\
\text { Mila B. }(5 ; 9)\end{array}$ & \\
\hline Catalan & $\begin{array}{c}\text { LS 3: one } \\
\text { language-one } \\
\text { environment }\end{array}$ & $\begin{array}{l}\text { Duna }(3 ; 11) \\
\text { Alba }(10 ; 6)\end{array}$ & Balanced \\
\hline
\end{tabular}


Out of sixteen children, seven $(43.75 \%)$ are growing in a context wherein no family language has been established. Four children (25\%) are exposed to the MaL as the family language at home, and five children $(31.25 \%)$ are exposed to the $\mathrm{HL}$ as the family language. By looking at the column on the right, on language dominance, we observe that nine children are classified as balanced. Interestingly, over half of the balanced children (55.6\%) are exposed to the HL as family language, and one third (33.3\%) have no family language. Let us turn now to those children who are dominant in Catalan. Notice that no Catalan dominant child is exposed to German as a family language. From the three Catalandominant children, two children have no family language. Finally, three out of sixteen children are dominant in the MaL German. Two of these children find MaL support via one of the parents, who is a native speaker of this language (LS1). Interestingly, choosing German as family language seems to be irrelevant.

To sum up, the parents of Catalan-dominant children have chosen to use an HL as their family language (Catalan or the other HL) or no family language at all. In any case, German was an option for none of the families. By contrast, $75 \%$ of the parents of German-dominant children use German as a family language. Therefore, we can see that the selection of an HL (Catalan or English) as a family language favours a balanced behaviour between the HL Catalan and the MaL German, since only two out of twelve children, without a family language or with an HL as family language, are German dominant.

Following the different family languages described in this section, we can examine how the children's exposure to their L1s is conveyed from the parental point of view. Nevertheless, it may be relevant to examine which language children use with their Catalanspeaking parents in order to see whether there is also consistency in the child's linguistic output in the HL. This aspect will be discussed in the following section.

\subsubsection{Children's Language to the Catalan-Speaking Parent}

Of sixteen children, thirteen have a Catalan-speaking mother, two have a Catalanspeaking father, and one receives input from two Catalan-speaking parents. All children are, thus, exposed to Catalan at least from one Catalan-speaking parent at home. Of all children, nine $(56.25 \%)$ speak Catalan with their Catalan-speaking parent, while seven also (or only) speak German or English with this parent.

Figure 5 shows the distribution of children's language dominance across the language they use with the Catalan-speaking parent. The first group considers the seven balanced children (blue bar) who always use Catalan or Catalan together with another HL, namely English in this case. Specifically, of seven balanced children, four speak Catalan, while three also speak English together with Catalan, and only one child combines Catalan with the MaL German. Put differently, almost $60 \%$ of the balanced children answer the Catalan-speaking parent in Catalan only, while $40 \%$ code-switch (two-thirds with another $\mathrm{HL}$, one-third with the MaL). Regarding the six German dominant children (green bar), we can observe that half of them only respond in German to their Catalan-speaking parents, while the other half use Catalan only. Finally, the group of Catalan-dominant children (red bar) exclusively use Catalan. Therefore, we can see that $13(81.25 \%)$ out of 16 children respond in Catalan (or code-mix) to the Catalan-speaking parent. This is the case even for three children (Pau, Alba and Dana) classified as German dominant. For the remaining three German-dominant children (Magalí, Jan and Julia K.), their parents have reported that they interact with their Catalan-speaking parent in their dominant language. These results clearly show that language competence is not directly linked to those child interactions with the HL parent; the balanced and half of the German-dominant children predominantly interact with the Catalan-speaking parent in Catalan. 


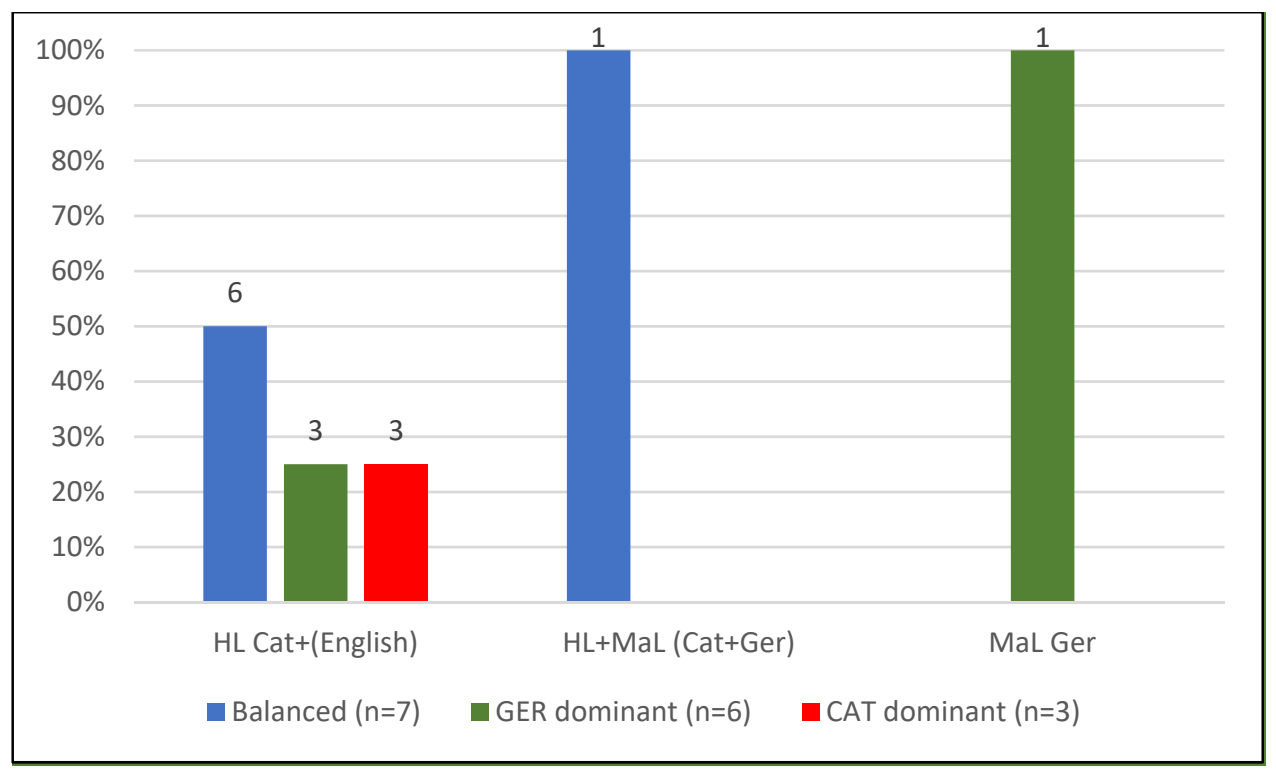

Figure 5. Children's language dominance and child's language to the Catalan-speaking parent.

Since the language that the child uses when addressing the Catalan-speaking parent might be not so much related to the child's language competence in his/her two or three L1s, but to the willingness to speak one language or the other with the Catalan-speaking parent (cf. Section 5.2), we examined whether the child's language when addressing the Catalan-speaking parent can be better explained in terms of the child's language fluency. Table 7 shows these results.

Table 7. Children's language fluency and child's language to the Catalan-speaking parent.

\begin{tabular}{cccc}
\hline & Catalan & Catalan+English/German & German \\
\hline Balanced fluency & $8(80 \%)$ & $2(20 \%)$ & \\
\hline Fluency towards German & $1(20 \%)$ & $1(20 \%)$ & $3(60 \%)$ \\
\hline Fluency towards Catalan & $1(100 \%)$ & & \\
\hline
\end{tabular}

From Table 7 we can observe that those children showing a higher fluency in German present a rather similar distribution between addressing their parents in German only $(\mathrm{N}=3,60 \%)$ and addressing them in Catalan (+English/German) in $40 \%$ of the cases. Now, considering children with a similar fluency in both languages or a higher fluency in the HL Catalan, we notice that they address their Catalan-speaking parent in Catalan only $(\mathrm{N}=9,81 \%)$ or in Catalan together with the child's other HL or the MaL, when supported at home $(\mathrm{N}=2,11 \%)$. Table 7 further shows that no child within these two categories (i.e., similar fluency in both languages and a higher Catalan fluency) exclusively employs German when talking to the Catalan-speaking parent.

In a nutshell, we have identified an interesting pattern for child-parent interactions in the HL for most children, namely that they mostly respond in Catalan to their Catalanspeaking parents, followed by using Catalan together with another HL or the MaL. However, it would also be interesting to examine how the non-native-Catalan-speaking parent can participate in a Catalan conversation with the child. If this is the case, this would mean that the family does not necessarily have to use a family language (or even the MaL) and that the child can, thus, interact in the HL with the non-native-Catalan-speaking parent as well. This is the focus of the following section. 


\subsubsection{Parents' Knowledge of the L2 Catalan}

With the aid of a Likert scale $(1-5 ; 1=$ not at all, $5=$ perfectly $)$, section $\mathrm{H}$ of the input questionnaire aimed to find out information on the four linguistic skills (understanding, speaking, writing, reading) that the non-native-Catalan-speaking parent might have. Given that Catalan is (one of) the heritage language(s) available in the families participating in this study, we wanted to examine whether the non-native-Catalan-speaking parent could participate (actively or non-actively) in a Catalan conversation, or whether families have to use a particular language (mostly the MaL) during family conversations.

Table 8 depicts the linguistic skills of the non-native-Catalan-speaking parents, taking into consideration two different Likert scales: (i) one focused on the communicative skills, that is, whether they can understand or speak Catalan, and (ii) another centred on the total score of Catalan skills, including not only the communicative skills but also the ability to read and write in Catalan. The column for the communicative skills allows for up to 10 points, while the total score allows for up to 20 points. In the case of exhibiting linguistic abilities in both oral and written skills, the total score indicates that they may have been instructed in Catalan, so they have learned this language in a formal setting. Therefore, parents with more than 10 points can be considered not only to be actively engaged in conversations in the L2 Catalan, but also to be able to use their reading and writing skills in this language.

Table 8. Linguistic skills of the non-native-Catalan-speaking parents.

\begin{tabular}{|c|c|c|c|c|}
\hline Child & Age & $\begin{array}{l}\text { Non-Native-Catalan- } \\
\text { Speaking Parent }\end{array}$ & $\begin{array}{c}\text { Communicative } \\
\text { Skills }\end{array}$ & $\begin{array}{l}\text { Total Knowledge of } \\
\text { Catalan (L2) }\end{array}$ \\
\hline Mila P. & $11 ; 2,18$ & \multirow{4}{*}{ L1 German } & \multirow{4}{*}{$5 / 10$} & \multirow{4}{*}{$7 / 20$} \\
\hline Nina $P$. & $13 ; 3,22$ & & & \\
\hline Dana P. & $5 ; 10,22$ & & & \\
\hline Kenya P. & $2 ; 11,21$ & & & \\
\hline Mila B. & $5 ; 9,10$ & \multirow{2}{*}{ L1 German } & \multirow{2}{*}{$3 / 10$} & \multirow{2}{*}{$3 / 20$} \\
\hline Nil B. & $4 ; 3,11$ & & & \\
\hline Julia K. & $7 ; 7,15$ & \multirow{2}{*}{ L1 German } & \multirow{2}{*}{$5 / 10$} & \multirow{2}{*}{$8 / 20$} \\
\hline Jan K. & $5 ; 2,25$ & & & \\
\hline Alba & $10 ; 6,22$ & None & - & - \\
\hline Júlia S. & $5 ; 9,16$ & L1 German & $5 / 10$ & $8 / 20$ \\
\hline David & $5 ; 8,18$ & L1 German & $5 / 10$ & $9 / 20$ \\
\hline Emily & $5 ; 1,16$ & L1 English & $10 / 10$ & $19 / 20$ \\
\hline Magalí & $4 ; 10,23$ & L1 German & $3 / 10$ & $5 / 20$ \\
\hline Pau & $4 ; 3,22$ & L1 Thai & $7 / 10$ & $12 / 20$ \\
\hline Duna & $3 ; 11,25$ & None & - & - \\
\hline Lena & $2 ; 8,10$ & L1 German & $4 / 10$ & $7 / 20$ \\
\hline
\end{tabular}

In the first step, we examined these four linguistic skills separately, and later on, we classified them into three groups: (a) good, (b) satisfactory and (c) insufficient communicative skills. Therefore, we were able to classify the non-native-Catalan-speaking parents into the following groups: (1) Between 11 and 20 points: those who can not only participate actively in a Catalan conversation since they understand and speak Catalan, but also write and read in Catalan (since they received formal instruction in the L2 Catalan); (2) between 5 and 10 points: those who can understand and speak Catalan to a certain extent; and (3) less than 5 points: those who cannot participate in a Catalan conversation, given that they cannot speak and/or understand Catalan. In this sense, parents belonging to group (1) 
would thus have some proficiency in oral and written skills, whereas those who scored very low (i.e., group (3)) do not. Parents belonging to group (2) have oral linguistic skills. ${ }^{19}$

Specifically, we observe in Table 8 that two out of nine non-native-Catalan-speaking parents, namely Pau's mother, and Emily's father, have good communicative skills (from 6 points) in Catalan that could allow them to actively participate in a Catalan conversation at home with their children and the Catalan-speaking parent. Regarding the total score of Catalan knowledge in the last column of Table 8, the same two non-native-Catalan-speaking parents go beyond 10 points. Another important result deals with the fact that three out of five German-dominant children have non-native-Catalan-speaking parents in group (3), that is, these parents do not have enough skills in Catalan to actively participate in a conversation. However, and surprisingly, the two parents who could be classified in group (1) have two children with differences in language dominance (one is balanced and the other one is German-dominant). Figure 6 compares the three groups of non-native-Catalan speaking parents to the language dominance of their children.

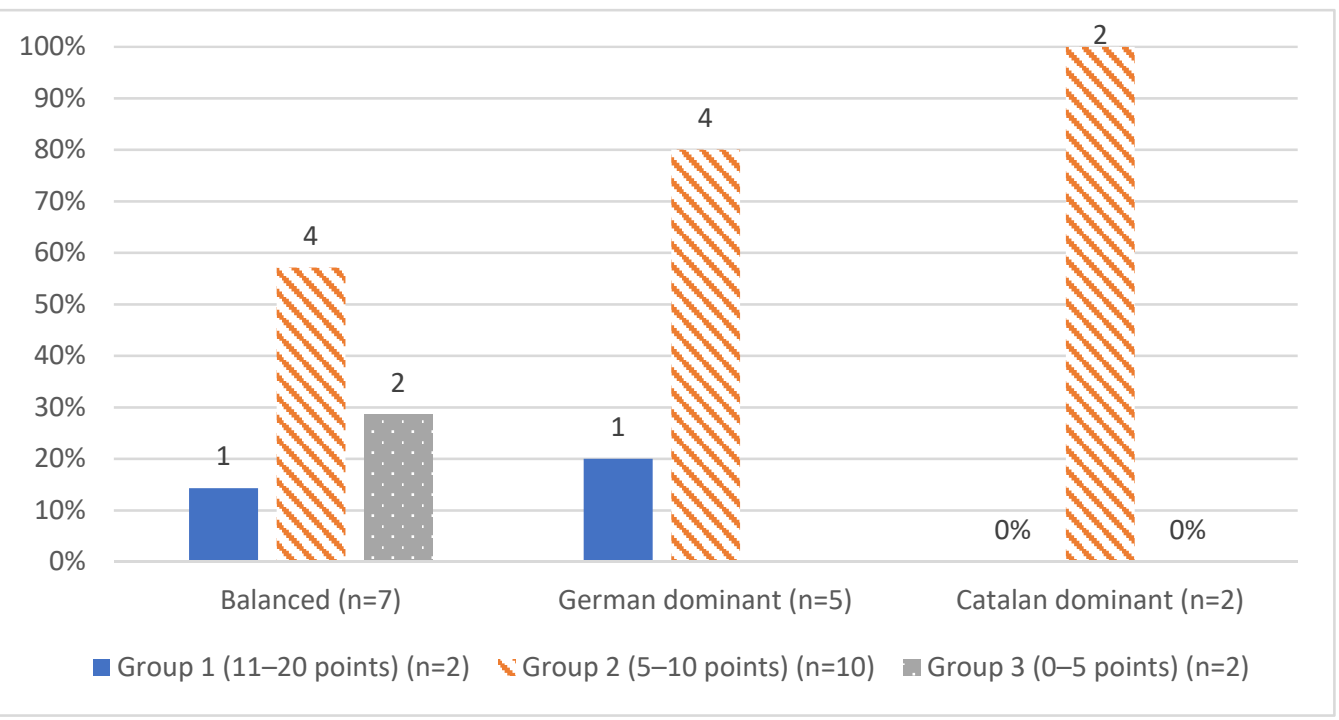

Figure 6. Children's language dominance and parents' knowledge of the L2 Catalan ${ }^{20}$.

We observe that parents belonging to group (1) are spread over the balanced and German-dominant categories, but are completely absent in the Catalan-dominant category. Interestingly, note that two out of five German-dominant children have non-native-Catalanspeaking parents belonging to groups (1) (in the blue bar) and (2) (in the orange bar) with a score between 5 and 10 points, while the two Catalan-dominant children have a parent with satisfactory linguistic skills in the L2 Catalan (i.e., they scored between 5 and 10 points). Put differently, the linguistic skills of the non-native-Catalan-speaking parents do not seem to influence the child's linguistic competence in the HL Catalan. A family setting in which Catalan-native and the non-native-Catalan-speaking parents are present later presents more elaborate language skills in this language. By these tokens, it might be interesting to compare parents' knowledge of L2 Catalan with the children's fluency in their L1s (instead of their language dominance). This is shown in Figure 7 below.

The data for the group of children with a fluency towards Catalan should be taken with caution, since only one child could be classified within this group. For the five children with a fluency towards German, we can observe that their non-native-Catalan-speaking parents belong to groups (2) and (3) according to their L2 Catalan skills. In the case of children who are fluent in a similar way in both Catalan and German, six parents belong to group (2), that is, they can actively participate in a Catalan conversation, while the non-native-Catalanspeaking parents of the remaining two children are indicated to have different linguistic skills (one belongs to group (1) and the other one to group (3)). Unfortunately, the data are too scarce to draw conclusions, yet the group of children with a clear fluency towards 
German comprises families whose non-native-Catalan-speaking parent only has basic linguistic skills in the L2 Catalan (i.e., they belong to group (3)). Finally, it is relevant that the single non-Catalan-speaking parent with the highest score (19/20 points) is the father of a child (Emily) who was assessed to be more fluent in Catalan than in the MaL German.

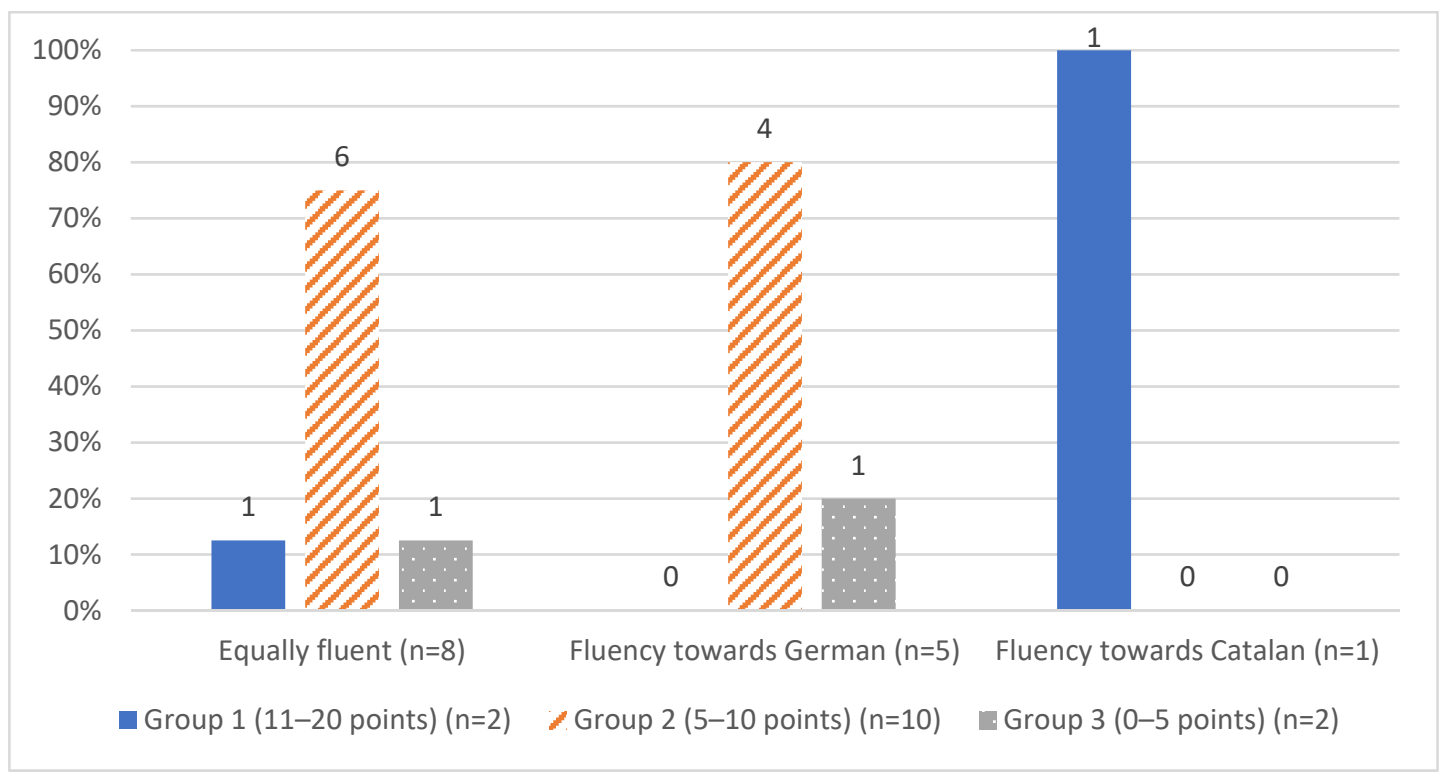

Figure 7. Children's fluency and parent's knowledge of the L2 Catalan.

After analysing the external factors related to German and Catalan exposure within the family scope, we analysed how children receive input throughout different activities, and whether they use the heritage and majority languages in production activities.

\subsubsection{Frequency of Comprehension and Production Activities}

In the input questionnaire, parents could evaluate how often their children performed different comprehension and production activities in Catalan and German. ${ }^{21}$ They evaluated each activity from 1 (less frequent) to 5 (more frequent). It is relevant to consider the difference between younger (younger than 6;0) and older (older than 6;0) children, given that they acquire some competencies starting in primary school, which are absent before 6;0; thus, the range of comprehension and production activities varies depending on the child's age. Therefore, the parents of younger and older children evaluated the overlapping of different comprehension and production activities, not only in the HL and MaL, but also in Spanish, English and Thai, ${ }^{22}$ depending on the children's L1s (see Tables 9 and 10 for children under $6 ; 0$ or older than $6 ; 0$, respectively).

Table 9. Comprehension and production activities by younger children $(<6 ; 0)$.

\begin{tabular}{ll}
\hline Comprehension Activities & Production Activities \\
\hline Listening to stories & Explaining stories \\
Watching cartoons & Singing songs \\
Listening to songs & Counting from 1 to 10 \\
& Talking to him/herself \\
\hline
\end{tabular}


Table 10. Production activities by older children $(>6 ; 0)$.

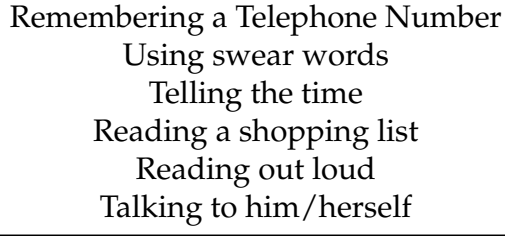

We analysed the total number of comprehension activities in Catalan (e.g., 8 points) and German (e.g., 10 points), and we performed a cross-multiplication: If 18 is $100 \%$ of child's comprehension activities, s/he presents $41 \%$ in Catalan and $59 \%$ in German. In addition, if the child is trilingual, we considered the $\mathrm{L}_{\mathrm{C}}$ and, therefore, the total percentage of $100 \%$ to be composed by Catalan, German and the $L_{C}$. This is the case, for instance, for Pau, who acquires Thai, together with Catalan and German, or for Emily, Nil, and Mila B., who acquire English, Catalan and German, simultaneously. Although these comprehension and production activities from Table 9 were addressed to younger children, most parents answered this section independently of the children's age.

As for the production activities, other activities different from the ones for children under 6;0 were chosen (cf. Table 10), since literacy from 6;0 onwards might manifest itself differently to that in the early years (i.e., until 6;0). Activities such as remembering a telephone number, using swear words or reproducing the shopping list show some kind of automatism and internalization of language, as depicted in some of the activities for younger children $(<6 ; 0)$ on Table 9. Parents with children older than $6 ; 0$ filled in these comprehension activities in the section for younger children (younger than 6;0). As one reviewer notes, comprehension activities such as reading/listening to stories are still of great importance in older years, and could act as predictors for language development associated with lexical and morphosyntactic abilities, as can watching cartoons or listening to songs. For this reason, we opted to keep comprehension activities for all age groups equal. From the group of four older children $(>6 ; 0)$, the parents of three children completed this section.

Table 11 reports the distribution of children according to language dominance and the extent to which they carry out comprehension and production activities in the heritage and majority languages. Likewise, we consider the percentage of frequency of the same activities in the $\mathrm{L}_{\mathrm{C}}$, such as Spanish, English and Thai. In other words, we analysed the total amount $(100 \%)$ of comprehension and production activities, considering all the languages to which children are exposed.

Table 11. Distribution of comprehension and production activities in Catalan, German (and $\mathrm{L}_{\mathrm{C}}$ ) according to language dominance.

\begin{tabular}{ccccc}
\hline & & Balanced & German Dominant & Catalan Dominant \\
\hline \multirow{2}{*}{$\begin{array}{c}\text { Comprehension } \\
\text { activities }\end{array}$} & Catalan & $39 \%$ & $33 \%$ & $54 \%$ \\
& German & $39 \%$ & $55 \%$ & $32 \%$ \\
\hline \multirow{2}{*}{ Production } & Other & $22 \%$ & $12 \%$ & $14 \%$ \\
activities & Geralan & $36 \%$ & $23 \%$ & $30 \%$ \\
& Other & $49 \%$ & $65 \%$ & $60 \%$ \\
\hline
\end{tabular}

Concerning comprehension activities, balanced children present the same frequency in Catalan and German (39\% for each). If we compare the data from German- and Catalandominant children, we find relevant results, since the language with the higher percentage of comprehension activities equals the child's dominant language. In other words, Germandominant children perform comprehension activities in German in 55\% of the cases, and in 33\% in Catalan. By contrast, Catalan-dominant children perform more comprehension 
activities in the HL (54\% in Catalan and 32\% in German). A total of $14 \%$ of comprehension activities carried out by Catalan dominant children (Duna, Mila P. and Nina) have to do with Spanish, while the only German dominant child with an $\mathrm{L}_{\mathrm{C}}$ (Pau) performs $12 \%$ of comprehension activities in Thai. Finally, balanced children show a high amount of exposure (22\%) in the $\mathrm{L}_{C}$ (English). This is the case for Mila B., Nil and Emily.

Let us now turn to production activities. Interestingly, the frequency of production activities in German for the Catalan-dominant group is similar to that of the Germandominant children. One reason for this resemblance might reside in the children's age (between 7;0 and 13;0): they are all older children attending primary/secondary German schools. The exposure to the MaL from the age of $6 ; 0$ onwards, due to schooling, significantly increases. For production activities in Catalan, balanced children are those who are more frequently engaged in these kinds of activities in the HL (36\%), followed by Catalan$(30 \%)$ and German- $(23 \%)$ dominant bi-/trilinguals. Note that, as expected, children receive more Catalan input than they actually produce (cf. Section 5.2.3, Table 7 with respect to language choice in the Catalan parents' directed speech according to children's language dominance). Considering German production activities, we observe an opposite trend: German-dominant children are engaged in more production $(65 \%)$ activities in German than the balanced $(49 \%)$ and Catalan-dominant $(60 \%)$ children. Concerning the production activities for the $\mathrm{L}_{\mathrm{C}}$, the percentage is lower than in the case of comprehension activities (15\% for balanced, $12 \%$ and $10 \%$ for German- and Catalan-dominant children, respectively).

\subsubsection{Language Exposure during the First Year of Life}

The results of Kozak et al.'s (2021) study, described in Section 1, are of relevance for our investigation, since they indicate that maternity leave have a positive impact on children's linguistic development in the early years of life. However, the fact that the length of maternity and linguistic development are not statistically correlated seems to speak against the idea that input quantity in these early years plays a decisive role. In this respect, we should keep in mind that Kozak et al.'s (2021) study focused on the linguistic development of English in the US, which means that the children participating in this study acquired English as L1 (only) and, thus, we were dealing with the monolingual acquisition of the MaL. For early multilingualism, the question concerning the relevance of the length of maternity/paternity leave, when the parent enjoying this time is the one speaking the HL, still needs to be explored. This is why we would like to examine this aspect in what follows. Since 14 out of 16 children have a Catalan mother, and they were also the ones enjoying more time at home than the respective non-native-Catalan-speaking fathers, it could be the case that these 14 children were more exposed to Catalan than German during their first year of life, and that this more frequent exposure to the HL Catalan-contrary to the acquisition of English as MaL in Kozak et al.'s (2021) study - might have a positive impact on HL acquisition. Table 12 shows the distribution of children regarding maternity and paternity leave, as well as the parents' respective L1s, and the languages to which the children were exposed during their first year of life.

As can be seen from Table 12 below, the majority of the children spent most of the time with Catalan-native mothers, specifically, at least during the first 6 months (Emily) and up to 18 months (Nil and Mila B.) before preschool. Duna and Alba spent their first year of life exclusively with their Catalan-speaking parents, given that the family nucleus is composed of native-Catalan-speaking parents only and, thus, they follow LS 3 (cf. Section 5.2.1). ${ }^{23}$ Note that only two children (Pau and Magalí) have been exposed to Catalan exclusively from their father. In this respect, only Pau's father enjoyed some time on paternity leave. The data described in Table 12 further imply that children were less exposed to German in these early years. These children, thus, started a greater exposure to German after maternity leave or with the start of preschool. At home, they were exposed to German from their German-native parents (i.e., most of the families followed OPOL-strategies, cf. LS1) and from social relationships with other German-native-speaking persons, such as grandparents, parents' friends, and older/younger siblings. In this sense, and having 
children's differences in terms of language dominance in mind from Section 5.1, our results suggest that there are no effects of language exposure during maternity leave on children's language dominance.

Table 12. Children's distribution according to maternity/paternity leave, parents' L1s and early language exposure.

\begin{tabular}{cccc}
\hline Children & Maternity Leave & Paternity Leave & Early Language Exposure \\
\hline Lena $(2 ; 8,10)$ & 10 months (Catalan) & 2 months (German) & Catalan/German \\
Cenya $(2 ; 11,21)$ & 12 months (Catalan) & & Can /German \\
Duna $(3 ; 11,25)$ & 7 months (Catalan) & Catan \\
Nil $(4 ; 3,11)$ & 18 months (Catalan/English) & 2 months (Catalan) & Catalan/German \\
Pau $(4 ; 3,22)$ & 10 months (Thai) & & Catalan/Thai \\
Magalí $(4 ; 10,23)$ & 12 months (German) & 2 months (English) & Catalan/English \\
Emily $(5 ; 1,16)$ & 6 months (Catalan) & & Catalan/German \\
Jan $(5 ; 2,25)$ & 12 months (Catalan) & Catalan/German \\
David $(5 ; 8,18)$ & 14 months (Catalan) & Catalan/German \\
Júlia S. $(5 ; 9,16)$ & 11 months (Catalan) & Catalan/German \\
Mila B. $(5 ; 9,10)$ & 18 months (Catalan/English) & & Catalan/German \\
Dana $(5 ; 10,22)$ & 12 months (Catalan) & & Catalan/German $/$ erman \\
Julia K. $(7 ; 7,15)$ & 12 months (Catalan) & Catalan \\
Alba $(10 ; 6,12)$ & 8 month (Catalan) & & Catalan/German \\
Mila P. $(11 ; 2,18)$ & 14 months (Catalan) & & Catalan/German \\
Nina $(13 ; 3,22)$ & 14 months (Catalan) & & \\
\hline
\end{tabular}

Previous studies have observed that input quantity is decisive in the child's first years of life (for monolingual acquisition cf. Rowe 2012; for early bilingual acquisition, see Pearson et al. 1997, but cf. Döpke 1992 for other results), yet other studies have shown that simultaneous and early bilinguals reflect a similar grammatical development (assessed via MLU, among other measures) when compared to their monolingual peers (Thordardottir 2015). With the beginning of preschool, children start to be more exposed to the MaL in different social contexts outside of home, or, for those families who follow LS 2 or LS 3 (cf. Table 5) are even exposed for the first time. Therefore, it could be the case that more or less exposure to the $\mathrm{MaL}$ in the younger years via preschool might be crucial for linguistic development in younger children. Since all participants had attended, or were attending, preschool at the time of testing, we decided to distribute the younger children (up to primary school age, namely aged 6;4) according to age (very young vs. young children) and exposure to the MaL outside home (i.e., in preschool); we compared this distribution to the children's language dominance. Type A are children up to 4;4 with two years of German exposure at preschool, whereas Type B are children between 4;4 and primary school age (i.e., 6;4) who had more than 2.6 years of German exposure in preschool and have just started attending primary school in the MaL German. We analysed data from 12 of the children, aged between 2;8 to 6;4. The other four children (Julia K., Alba, Mila P and Nina) are not considered in the following Figure 8, since they are older than 6;4 years.

While five children are very young (Type A), and it can thus be claimed that the LS conveyed at home might have a strong impact on the child's language dominance, seven children were classified as Type B because they were exposed to German in kindergarten for at least the last two years. Moreover, all very young children are exposed to Catalan at home from their mothers, the ones who enjoyed (longer) maternity leave. Of the five children (Type A), four are balanced bilinguals, and the remaining child belonging to this group is Catalan dominant (i.e., Duna, whose mother and father are Catalan native speakers and, thus, follow LS 3, cf. Section 5.2.1). For the children belonging to Type B (young children), we can see two different trends: three of the children are balanced (all receiving Catalan input from their mothers), and four children are German dominant. The group of German-dominant children is composed of Magalí, Pau, Jan, and Dana. Regarding the information on maternity leave, Magalí was exposed to German, Pau received Thai from 
his mother, and Jan and Dana heard Catalan from their mothers. From this description of the data, we can conclude that over $70 \%$ of the very young children (Type A) are balanced and, interestingly, none of them can be classified as German dominant. By contrast, 50\% of the young children with more than 2;6 years of German exposure in preschool (Type B) exhibit dominance in the MaL German. These results seem to speak in favour of a relevant impact of family language strategies during early childhood, especially before, or with less than two years of extensive exposure to the MaL outside home (i.e., in kindergarten).

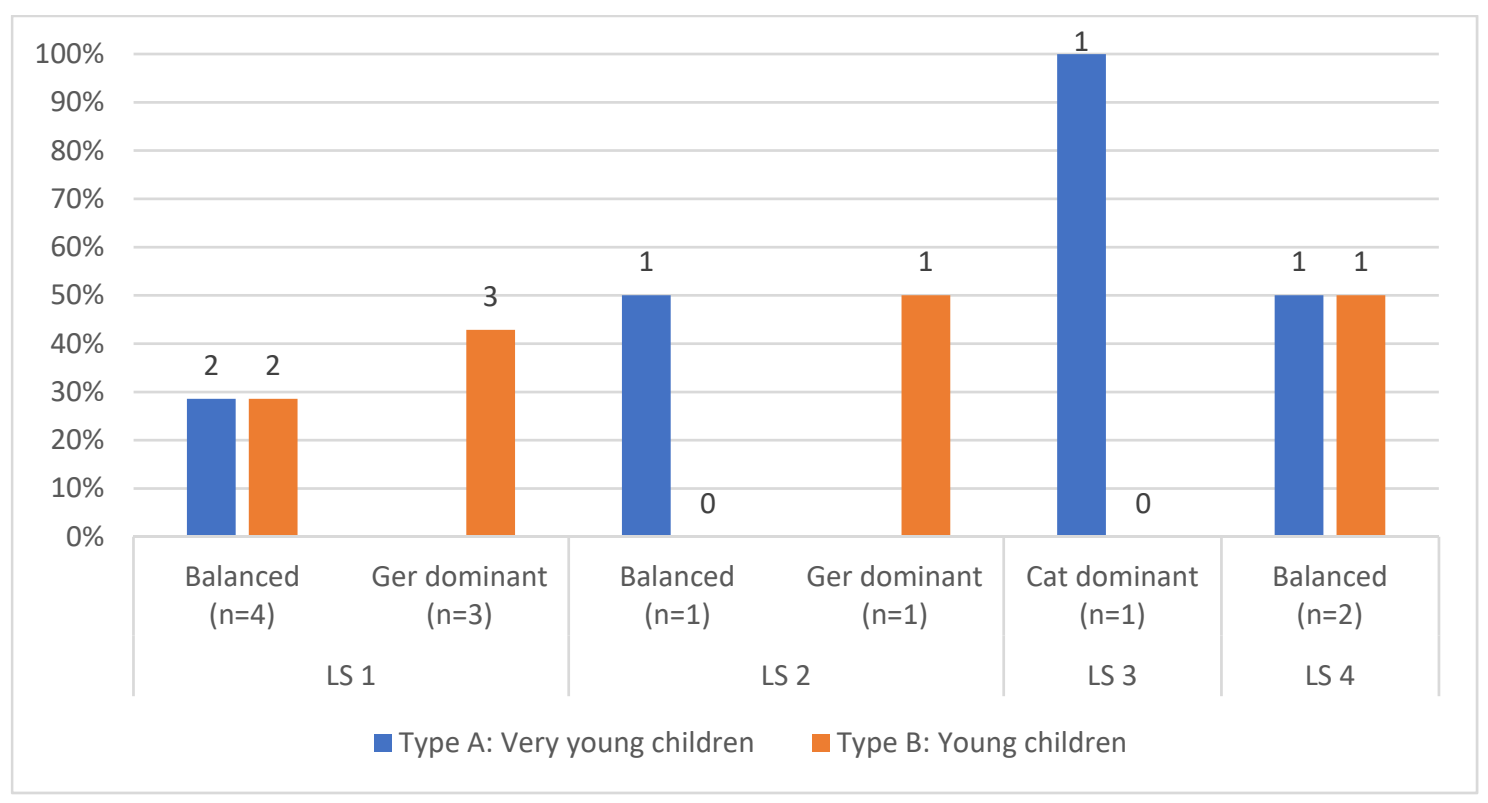

Figure 8. Age groups and early language exposure according to children's language dominance.

The following Section 5.2.7 summarises the different child-external factors, and brings them together with the children participating in this study.

5.2.7. Combination of Different Child-External Factors for Language Dominance: A Descriptive Approach

After analysing the different child-external factors that could play an important role in language dominance independently, we examined whether a possible influence towards language dominance depends on combining several of these factors. Since the data sample is rather small for a statistical analysis, we will discuss the combination of different childexternal factors in a descriptive way. Table 13 summarises the external factors we analysed in previous Sections 5.2.1-5.2.6.

In terms of language dominance, and regarding the seven balanced children, we observe that they have all received Catalan and German/English input during their first year of life. In addition, while four of them only respond in Catalan to their Catalanspeaking mother, three also use English/German, i.e., they code-switch. For bilingual children whose mother is the Catalan-native parent, we observe that most fathers only speak/understand the L2 Catalan. Now, let us consider the German-dominant children. Out of six children, four were exposed to German, together with Catalan, from birth, and two received German input from the environment later on; Pau was exposed to Catalan and Thai at home, and Alba only received Catalan input from birth, and was raised in Catalonia until age 4. Furthermore, for this group of six German-dominant children, we can observe that the father is the Catalan-speaking parent in two cases. Moreover, half of the German-dominant children only speak German to their Catalan-speaking parents. Only Pau's mother belonged to group (1), since she scored 19 out of 20 points for the L2 Catalan linguistic skills. However, we do not know whether she also speaks Catalan in the family context. Finally, as regards (the three) Catalan dominant children, the group is somehow 
quite heterogeneous: While Duna only receives Catalan input at home from both parents, Mila P. and Nina were exposed to Catalan and German during their first year of life.

Table 13. Child-external factors ordered according to children's language dominance.

\begin{tabular}{|c|c|c|c|c|c|}
\hline Children & $\begin{array}{l}\text { Input during } \\
\text { First Year of Life }\end{array}$ & $\begin{array}{l}\text { Catalan Parent (Child's } \\
\text { Language(s) to the } \\
\text { Catalan Parent) }\end{array}$ & $\begin{array}{c}\text { Parents' } \\
\text { Linguistic Skills } \\
\text { in the L2 Catalan }\end{array}$ & $\begin{array}{l}\text { Language } \\
\text { Dominance }\end{array}$ & $\begin{array}{l}\text { Language } \\
\text { Fluency }\end{array}$ \\
\hline Lena $(2 ; 8,10)$ & CAT/GER & Mother (CAT/GER) & (2) Satisfactory & Balanced & None \\
\hline Kenya $(2 ; 11,21)$ & CAT/GER & Mother (CAT) & (2) Satisfactory & Balanced & None \\
\hline Nil $(4 ; 3,11)$ & CAT/GER & Mother (CAT /ENG) & (3) Insufficient & Balanced & GER \\
\hline Emily $(5 ; 1,16)$ & CAT/ENG & Mother (CAT) & (1) Good & Balanced & CAT \\
\hline David $(5 ; 8,18)$ & CAT/GER & Mother (CAT) & (2) Satisfactory & Balanced & None \\
\hline Júlia S. $(5 ; 9,16)$ & CAT/GER & Mother (CAT) & (2) Satisfactory & Balanced & None \\
\hline Mila B. $(5 ; 9,10)$ & CAT/GER & Mother (CAT /ENG) & (3) Insufficient & Balanced & None \\
\hline Pau $(4 ; 3,22)$ & $\mathrm{CAT} / \mathrm{THAI}$ & Father (CAT) & (1) Good & GER dominant & None \\
\hline Magalí $(4 ; 10,23)$ & CAT/GER & Father (GER) & (2) Satisfactory & GER dominant & None \\
\hline Jan $(5 ; 2,25)$ & CAT/GER & Mother (GER) & (2) Satisfactory & GER dominant & GER \\
\hline Dana $(5 ; 10,22)$ & CAT/GER & Mother (CAT) & (2) Satisfactory & GER dominant & None \\
\hline Julia K. $(7 ; 7,15)$ & CAT/GER & Mother (GER) & (2) Satisfactory & GER dominant & GER \\
\hline Alba $(10 ; 6,12)$ & CAT & Mother (CAT) & None & GER dominant & None \\
\hline Duna $(3 ; 11,25)$ & CAT & Parents (CAT) & None & CAT Dominant & None \\
\hline Mila P. $(11 ; 2,18)$ & CAT/GER & Mother (CAT) & (2) Satisfactory & CAT Dominant & None \\
\hline Nina $(13 ; 3,22)$ & CAT/GER & Mother (CAT) & (2) Satisfactory & CAT Dominant & GER \\
\hline
\end{tabular}

\section{Discussion and Future Research}

The aim of this paper was twofold. First, we wanted to describe the Catalan community in the diaspora, particularly in Germany, and present those studies that have contributed to a better understanding of the transmission, promotion, and acquisition of Catalan as an HL outside the Catalan-speaking regions of Spain. Second, we summarized the previous literature on HL promotion, and examined some input quantity and quality factors in a study carried out with sixteen bi- and trilingual children, mostly raised with Catalan as an HL in Hamburg (Germany).

To examine the RQ1 and H1, we considered the LS, the language in which the child addresses the Catalan-speaking parent, and how language dominance/language fluency might relate to these two first factors. The results suggest that the family's LS does not have a direct impact on the child's language competence, at least taking all 16 children into consideration (but cf. the study of Arnaus Gil (2022) for other results when Spanish/German are the HL). However, if we consider the most frequently chosen LS, namely OPOL (LS 1), and relate it to the possibility of having a family language available (cf. Section 5.2.2), we observe that the choice of German as a family language has a negative impact on language dominance of the HL Catalan; the number of children that show dominance towards the MaL is higher if German is conveyed as family language than for those families who decided to have no family language at all. To sum up, and focusing on language dominance, Catalan-dominant and balanced children have mostly indicated to not have a family language. As for the group of German-dominant children, we identify half of the families as having chosen German as a family language. Turning to the child's language choice when interacting with the Catalan-speaking parent, $81.25 \%$ of all children respond in Catalan only, or Catalan together with English/German. This result indicates that these children either respond in the desired language (i.e., the HL) to the Catalan-speaking parent or code-switch. Even for the three (out of six) children classified as dominant in the MaL, we observe this pattern. When considering language fluency, the main result was that the group of children considered as being similarly fluent in both languages, and those with a higher fluency in Catalan, address their Catalan-speaking parent in Catalan (+English/German). Although these results for RQ1 are applied to a small sample and, therefore, they must be interpreted with caution, we can conclude that LS and family language together have a direct impact on a child's linguistic competence. 
Moreover, language fluency also seems to better explained the results on child's speech addressed to the Catalan-speaking parent.

RQ2 and H2 follow up on some previous studies by De Houwer $(2004,2007)$ and Arnaus Gil et al. (2019), which observed some correlation between the linguistic skills in the HL of the non-native parent and the child's HL competence. At first sight, the results obtained in our study speak against such a relationship, since those non-native parents who have indicated that they understand and/or speak L2 Catalan to a certain extent (group (2), 5-10 points) are spread over the three language-dominance categories. However, when considering language fluency, we observe an interesting pattern, that is, those children with a higher fluency in the MaL are generally those with parents who achieved fewer than 5 points in the HL (i.e., belonging to group (3)). From these results, it is not clear how the Catalan linguistic skills from the non-native parent might promote a higher fluency in the $\mathrm{HL}$, or even a similar fluency between the child's L1s. Yet, we can conclude that, when the child displays a fluency towards German, the points obtained in the Likert scales, to assess the linguistic skills in the L2 Catalan from the non-native parent, are less than 5 (i.e., group (3)).

RQ3 and H3 aimed at exploring the relationship between (early) age and the impact of input quantity in the child's early years, already noted in previous literature (Gathercole 2007; Pearson et al. 1997; Kozak et al. 2021). In this sense, we analysed the information on input exposure in the children's first year of life, and related it to cumulative exposure to German and Catalan and maternity/paternity leave. The results indicate no relation between cumulative exposure to German and Catalan, age, or language dominance. Considering input exposure during the first year of life, there seems to be an impact on the LS used during (very) early childhood. Specifically, three out of four children belonging to the youngest group are exposed to LS 1 and can be classified as balanced. These results are in line with those reported in Arnaus Gil (2022) on Spanish and German HL in Germany and Spain, respectively, in which age and LS seem to be tightly linked to language competence in the child's early years.

RQ4 and H4 were focused on examining the relationship between children's language dominance and the extent to which they receive and produce German and Catalan (and $\mathrm{L}_{\mathrm{C}}$ ) in different comprehension and production activities. The results provide relevant information concerning the need to look for a similar frequency of activities in both languages, or even promoting more comprehension and production activities in the HL Catalan. These results suggest that, while Catalan-dominant and balanced children present higher percentages of Catalan comprehension activities, the German dominant group displays a lower amount of HL exposure. However, all children, irrespective of their language dominance, are engaged more frequently in German rather than Catalan production activities. These findings reflect the results on the child's language choice to the Catalan-speaking parent: out of sixteen children, three respond in German and another three code-switch (Catalan with English or German) to their Catalan-speaking parents ( $n=6,37.5 \%)$.

Finally, RQ5 and its corresponding hypothesis tried to approach the role of a family's decision on using a family language. We hypothesized that if a family decides to use the HL as their family language, this should positively influence the child's language competence in the HL; this would give the HL more opportunities to be used in more everyday situations, and with more family members. The descriptive results in Section 5.2.2 seem to indicate that the parents of Catalan-dominant children either have chosen to use the HL as the family language, or display no family language at all. Put differently, the majority language was an option for none of the families. By contrast, the parents of those children classified as having German dominance, and who have decided to use a family language, determined German as the family language $75 \%$ of the time.

Future investigations are needed to collect more data and establish more homogeneous groups for analysing the different child-external factors examined along these lines, in order to obtain more robust results. Likewise, other analyses with other quantity and quality factors proposed in previous literature must be considered, such as the number of 
trips to the Catalan-speaking territories per year, the language exposure not only during the first year of life but also during primary and secondary school (in older children), and children's linguistic choice when talking to siblings, grandparents and other socially close members. Finally, it is also essential to know the children's linguistic attitudes towards the $\mathrm{HL}$, that is, how important it is for the child to acquire the HL, and how this factor may affect HL promotion in late childhood years.

Author Contributions: Conceptualization, L.A.G. and A.J.-G.; methodology, L.A.G. and A.J.-G.; software, Microsoft Office, SPSS.; validation, L.A.G. and A.J.-G.; formal analysis, L.A.G. and A.J.-G.; investigation, L.A.G. and A.J.-G.; resources, L.A.G.; data curation, L.A.G. and A.J.-G.; writing—original draft preparation, L.A.G. and A.J.-G.; writing-review and editing, L.A.G. and A.J.-G.; visualization, L.A.G. and A.J.-G.; supervision, L.A.G. and A.J.-G.; project administration, L.A.G.; funding acquisition, L.A.G. All authors have read and agreed to the published version of the manuscript.

Funding: This research was funded by University of Hamburg grant number U4513EXP190102.

Institutional Review Board Statement: Not applicable.

Informed Consent Statement: Informed consent was obtained from all subjects involved in the study.

Data Availability Statement: The data presented in this study are available on request from the corresponding author. The data are not publicly available due to data privacy protection.

Conflicts of Interest: The authors declare no conflict of interest.

\section{Appendix A}

Table A1. Instances of questions on input quantity and quality factors being treated in the parental questionnaire.

\section{Input Quantity Factors}

Quant de temps a la setmana calculeu que passa la vostra filla/el vostre fill amb les persones

Amount of input següents del seu entorn?/Wie viel Zeit schätzt Ihr, dass Euer Kind mit den Personen seiner Umgebung verbringt? (How much time per week do you estimate your daughter/son spends with the following people in their environment?)

Amb quina quantitat $i$ què ha parlat cada una de les persones adultes que viuen a casa vostra amb l'infant durant cada un dels anys abans de començar amb la llar d'infants?/Wie viel und was hat jede

Cumulative input erwachsene Person im Haus mit dem Kind jedes Jahr vor Kitaeintritt gesprochen? (How much, and what language, did each of the adults (living in your home) talk with the child during each of the years before they started kindergarten?)

\begin{tabular}{|c|c|}
\hline Language strategy (LS) & $\begin{array}{l}\text { Qui parla què AMB L’INFANT?/Wer spricht was MIT DEM KIND? (Who speaks what with } \\
\text { the child?) }\end{array}$ \\
\hline Language constellation & $\begin{array}{l}\text { Teniu una llengua o llengües familiars?/Habt Ihr eine Familiesprache(n)? (Do you have (a) family } \\
\text { language(s)?). } \\
\text { Quina llengua empreu per fer els deures de l'escola?/Welche Sprache nutzt Ihr für die Anfertigung } \\
\text { der Hausaufgaben? (What language do you use to do school homework?) }\end{array}$ \\
\hline \multicolumn{2}{|r|}{ Input quality factors } \\
\hline $\begin{array}{l}\text { Family's linguistic } \\
\text { competencies }\end{array}$ & $\begin{array}{l}\text { Com valores els teus coneixements en les llengües següents?/Wie schätzt Du Deine Kompetenzen in } \\
\text { den folgenden Sprachen? (How do you value your knowledge in the following languages?) }\end{array}$ \\
\hline Cultural contact & $\begin{array}{l}\text { Quants cops a l'any aneu a una regió catalano-parlant?/Wie oft besucht Ihr eine Katalanisch } \\
\text { sprachige Region pro Jahr? (How many times per year do you go to a Catalan-speaking region?) } \\
\text { Quan sou a la regió catalano-parlant, quina llengua/quines llengües parleu i amb quina } \\
\text { freqüència?/In der Katalanisch sprachigen Region, welche Sprache(n) nutzt Ihr und wie oft werden } \\
\text { sie benutzt? (When you are in the Catalan-speaking region, what language(s) do you speak and } \\
\text { how often?) }\end{array}$ \\
\hline
\end{tabular}


Table A1. Cont.

\section{Input Quantity Factors}

Amb quina freqüència penseu que la vostra filla/el vostre fill utilitza una de les llengües durant les següents activitats?/Wie schätz Ihr ein, wie häufig Eure Tochter/Euer Sohn die Muttersprachen bei den folgenden Aktivitäten verwendet? (How often do you think your daughter/son uses one of the languages during the following activities?)

Linguistic domains Com de sovint creieu que el vostre fill/la vostra filla empra les llengües maternes en les seves activitats cotidianes?/Wie oft schätzt Ihr ein, dass Euer Sohn/Eure Tochter die Muttersprachen für die alltäglichen Aktivitäten nutzt? (How often do you think your child uses his/her mother tongues in everyday quotidian activities?)

Importance of bilingualism/multilingualism to be supported in the family by its family members
Com d'important és per a tu entendre/parlar/escriure/llegir català?/Wie wichtig ist für Dich Katalanisch verstehen/spechen/schreiben/ lesen? (How important is it for you to understand/speak/write/read in Catalan?)

\section{Notes}

years;months.

2 Most importantly, both studies dealt with HLs that find some kind of support in the community where these bilingual children grow up. Particularly, both studies recruited bilingual families in Florida. Furthermore, Gathercole (2007) could count on bilingual families in Wales as well. In this respect, these families could take advantage of certain HL support outside the home, i.e., in the community.

3 Authors acknowledge that this is contrary to previous work, and this might be due to the fact that their sample did not contain enough extreme cases, i.e., mothers who took less than 2 weeks and more than 12 weeks.

4 Unfortunately, no information on the Catalans living in Germany who were born in this country and whose origin is the Valencian Community is available.

5 As one reviewer correctly observes, it might be the case that not all Catalan families in the diaspora choose to register their children who are born in Germany in the Catalan-speaking regions in Spain. In this respect, the number of Catalan families from Catalonia and the Balearic Islands living in the diaspora might actually be underrepresented; therefore, it consists of a larger community than the one we can interpret from the official statistical resources.

6 These studies also investigate the Galician community in this city.

7 Moreover, interviews with five Galician families with a total of 10 children were also carried out.

8 These statistical results are also valid for Spanish, but not applicable for German (Arnaus Gil et al. 2020).

9 We agree with one reviewer that adjusting the tasks that were carried out in the language recordings depending on child's age might indirectly mask children's productions. Put differently, games such as Guess Who trigger shorter, monoclausal sentences, while talking about a favourite series might elicit longer sentences as well as more subordinate and relative clauses.

Although this study focuses on German-Catalan bilingual children, four children are trilingual: three of them speak English and the other speaks Thai. We also recorded them in English and Thai conversations with their parents or other native adults. We are in the process of transcribing and analyzing these data.

11 Regarding previous bilingual studies that have used MLU and fluency in order to assess language proficiency in early childhood, we are well aware of the fact that Catalan and German differ in some aspects and these differences might thus affect the calculated MLU values for each language. For instance, German belongs to the family of non-pro-drop languages, whereas Catalan, as well as other Romance languages, can be considered pro-drop languages. In this sense, we decided to follow previous empirical studies for the German-Romance combinations as in Schmeißer et al. (2016), specifically by considering Catalan-omitted subjects in the MLU calculation. For a further description and discussion of how MLU values can be inferred across languages, cf. Yip and Matthews $(2000,2006)$ and Müller et al. (2007), among others. One example of a question for each factor in Table 2 can be consulted in Appendix A.

This research question will be answered in our study with data from a cross-sectional study with 16 bi- and trilingual children. However, longitudinal data with bi- and trilingual children would contribute to answering this question as well.

However, its use has been controversial, when sentence length, measured in terms of MLU, is linked to syntactic complexity and, thus, to language competence (cf. Köppe 1997 and Döpke 1992 for contrary views on this topic and Arencibia Guerra 2008 for a critical discussion).

15 Yet, using MLU to calculate language proficiency and language dominance for children past age 5 or 6 remains controversial, as one reviewer notes, since children are well aware of numerous communication and linguistic skills that might shorten or lengthen their sentences. However, there are empirical studies that have used other performance criteria (e.g., words per minute) 
with young adults with the same objective, in the acquisition of Romance languages as heritage languages (Schmitz and Scherger 2017; Diaubalick et al. 2020). Nonetheless, we are aware of the limitations of our study concerning the use of MLU to measure language dominance on older children. Future research should add other forms of language assessment in the child's L1s.

The oldest child, Nina, presents a FluencyD of $12.63 \mathrm{w} /$ minute. Strictly speaking, we thus classified her as having a higher language fluency in Catalan. However, we think it could be reasonable to consider her (still) as having a similar language fluency in her two L1s, since FluencyD is extremely close to the boundary of $11.99 \mathrm{w} / \mathrm{min}$. Put differently, Nina is less than one word per minute away ( 0.64 words) from being regarded as having a similar language fluency in both L1s. In this sense, the distribution of the sixteen children according to language fluency would, thus, be: ten children with similar language fluency (62.5\%), five participants with a higher language fluency in German (31.25\%), and one child showing a higher fluency in Catalan (6.25\%). From now on, we will follow this approach.

Nina has also been counted in this group and not in the group 'higher rates of language fluency in German', for the reasons we specified in the previous footnote.

18 Since the different groups of children across the external factors are heterogeneous and, following the suggestion of one reviewer, we decided to describe the results, leaving statistical analyses aside.

19 As a reviewer correctly points out, only having oral skills does not necessarily imply less linguistic competence. In this respect, we have used the values of the Likert scales on speaking, understanding, reading, and writing in order to best capture the linguistic status of the L2 Catalan in non-native parents.

Note that data from Alba and Duna are missing, since they only have Catalan-speaking parents.

This section of the input questionnaire is based on the work by Torregrossa and Bongartz (2018).

Even though this paper only focuses on German and Catalan responses, the total percentages of each child also consider the percentage of the $\mathrm{L}_{C}$ (Spanish, English, or Thai); that is, trilingual children present less than $100 \%$ of frequency if Catalan and German responses are combined, given that parents explained that the children also perform activities in the $L_{C}$.

Moreover, Alba is the only child who was born in a Catalan-speaking region and did not move to Germany until age 4;0.

\section{References}

Aalberse, Suzanne, Ad Backus, and Pieter Muysken. 2019. Heritage Languages. A Language Contact Approach. Amsterdam/Philadelphia: John Benjamins Publishing Company.

Arnaus Gil, Laia. 2022. Spanish and German as heritage and majority languages in early multilingual acquisition: Family Language Policies and other child-external factors for heritage language competence. International Journal of Multilingualism. To appear. [CrossRef]

Arnaus Gil, Laia, and Natascha Müller. 2020. Els verbs copulatius catalans ésser i estar i la seva adquisició en edats primerenques. Un estudi sobre el trilingüisme precoç a Espanya i Alemanya. In Contact, variation, and change in Romance and beyond. Studies in honor of Trudel Meisenburg. Edited by Gabriel, Christoph, Andrea Pešková and Maria Selig. Berlin: Erich Schmidt, pp. 283-300.

Arnaus Gil, Laia, Natascha Müller, Marina Hüppop, Meike Poeste, Elena Scalise, Nadine Sette, Abira Sivakumar, Mabel Tirado Espinosa, and Katharina Sonja Zimmermann. 2019. Trilinguismus. Eine Einführung mit den Sprachen Deutsch, Französisch, Katalanisch und Spanisch. Tübingen: Narr.

Arnaus Gil, Laia, Natascha Müller, Nadine Sette, and Marina Hüppop. 2020. Active bi- and trilingualism and its influencing factors. Applied Psycholinguistics. [CrossRef]

Arencibia Guerra, Lastenia. 2008. Sprachdominanz bei Bilingualen Kindern mit Deutsch und Französisch, Italienisch oder Spanisch als Erstsprachen. Bergische Universität Wuppertal. Available online: http://elpub.bib.uni-wuppertal.de/edocs/dokumente/fba/ romanistik/diss2008/arenguerra/da0805.pdf (accessed on 9 February 2022).

Braun, Andreas, and Tony Cline. 2014. Language Strategies for Trilingual Families. Parents' perspectives. Bristol: Multilingual Matters.

Buades Crespí, Joan, Mariantònia Manresa Montserrat, Antoni Marimon Riutort, and Margalida Mas Barceló. 2001. El Moviment Associatiu Balear a L'exterior. L'emigració de les Illes Balears a Ultramar. Conselleria de Presidència, Govern de les Illes Balears. Benissalem: Gràfiques Rubines, SL.

Cantone, Katja Francesca, Tanja Kupisch, Natascha Müller, and Katrin Schmitz. 2008. Rethinking language dominance in bilingual children. Linguistische Berichte 215: 307-43.

Casesnoves-Ferrer, Raquel, and Eva Juarros-Daussà. 2012. La influencia de la política lingüística en la transmisión del catalán y del gallego dentro y fuera de sus fronteras. In Empiricism and Analytical Tools for 21 Century Applied Linguistics. Edited by Elorza Izaskun, Ovidi Carbonell, Reyes Albarrán, Blanca García and Mirian Pérez-Veneros. Salamanca: Ediciones Universidad Salamanca, pp. 861-74.

Casesnoves-Ferrer, Raquel, and Eva Juarros-Daussà. 2015. El catalán entre las dos lenguas más habladas del mundo. In Lengua Española, Contacto Lingüístico y Globalización. Edited by R. Terborg and A. Alarcón. México: Universidad Nacional Autónoma de México, pp. 463-92.

CEVEX, Centre de Valencians a l'Exterior. 2020. Generalitat Valenciana. Available online: http:/ /cevex.gva.es/va/ (accessed on 11 December 2020). 
Chevalier, S. 2015. Trilingual Language Acquisition. In Contextual Factors Influencing Active Trilingualism in Early Childhood. Amsterdam: Benjamins.

Cobo-Lewis, Alan B., Rebecca E. Eilers, Barbara Zurer Pearson, and Vivian C. Umbel. 2002. Interdependence of Spanish and English knowledge in language and literacy among bilingual children. In Language and Literacy in Bilingual Children. Edited by K. Oller and R. Eilers. Clevedon: Multilingual Matters, pp. 118-34.

De Houwer, Annick. 2004. Trilingual input and children's language use in trilingual families in Flanders. In Trilingualism in Family, School and Community. Edited by C. Hoffmann and J. Ytsma. Chlevedon: Multilingual Matters, pp. 118-35.

De Houwer, Annick. 2007. Parental language input patterns and children's bilingual use. Applied Psycholinguistics 28: 411-24. [CrossRef]

De Houwer, Annick. 2009. Bilingual First Language Acquisition. Bristol: Multilingual Matters.

Diaubalick, Tim, Pedro Guijarro-Fuentes, and Katrin Schmitz. 2020. Tense and aspect in Spanish heritage speakers living in Germany. In New Trends in Language Acquisition within the Generative Perspective, Studies in Theoretical Psycholinguistics. Edited by P. GuijarroFuentes and C. Suárez-Gómez. Dordrecht: Springer, pp. 49-70.

Döpke, Susanne. 1988. The role of parental teaching techniques in bilingual German-English families. International Journal of the Sociology of Language 72: 101-12. [CrossRef]

Döpke, Susanne. 1992. One Parent One Language: An Interactional Approach. Amsterdam: John Benjamins.

Döpke, Susanne. 2000. The interplay between language-specific development and cross-linguistic influence. In Cross-Linguistic Structures in Simultaneous Bilingualism. Edited by S. Döpke. Amsterdam: John Benjamins, pp. 79-103.

Dunn, Lloyd, Claudia Thériault-Whalen, and Leota Dunn. 1993. Échelle de vocabulaire en images Peabody. In Adaptation Française du Peabody Picture Vocabulary Test Revised. Toronto: Pearson Canada Assessment Inc.

Gathercole, Virginia. 2007. Miami and North Wales, so far and yet so near: A constructivist account of morphosyntactic development in bilingual children. International Journal of Bilingual Education and Bilingualism 10: 224-47. [CrossRef]

GENCAT. 2020. Generalitat de Catalunya. Available online: https://web.gencat.cat/ca/inici (accessed on 11 December 2020).

Grosjean, Francois. 2001. The bilingual's language modes. In One Mind, Two Languages: Bilingual Language Processing. Edited by J. Nicol. Oxford: Blackwell, pp. 1-22.

Hager, Malin. 2014. Der Genuserwerb bei Mehrsprachig Aufwachsenden Kindern-Eine Longitudinale Untersuchung Bilingualer und Trilingualer Kinder der Sprachenkombinationen Deutsch-Französisch/Italienisch/Spanisch, Französisch-Italienisch/Spanisch und Deutsch-Spanisch-Katalanisch. Bergische Universität Wuppertal. Available online: http:/ / elpub.bib.uni-wuppertal.de/ edocs/dokumente/fba/romanistik/diss2014/hager/da1401.pdf (accessed on 9 February 2022).

Hawkey, James W. 2011. Towards an understanding of the contemporary sociolinguistic situation in the Pyrénées-Orientales: What questions need to be asked? Cahiers AFLS 15: 36-52.

Hoffmann, Charlotte. 1985. Language acquisition in two trilingual children. Journal of Multilingual and Multicultural Development 6: 479-95. [CrossRef]

IBESTAT, Institut d'Estadística de les Illes Balears. 2020. Govern de les Illes Balears. Available online: https://ibestat.caib.es/ibestat/ page? \&p=inicio\&lang=ca (accessed on 11 December 2020).

IDESCAT, Institut Nacional d'Estadística de Catalunya. 2020. Generalitat de Catalunya. Available online: https://www.idescat.cat (accessed on 11 December 2020).

INE, Instituto Nacional de Estadística. 2020. Gobierno de España. Available online: https://www.ine.es (accessed on 11 December 2020).

Juan-Garau, Maria, and Carmen Pérez-Vidal. 2001. Mixing and pragmatic parental strategies in early bilingual acquisition. Journal of Child Language 28: 59-86. [CrossRef]

Juarros-Daussà, Eva. 2013. Language transmission among Catalan and Galician Immigrants in New York City. In Selected Proceedings of the 6 th Workshop on Spanish Sociolinguistics. Edited by A. M. Carvalho and Sa Beaudrie. Somerville: Cascadilla Proceedings Project, pp. 148-57.

Juarros-Daussà, Eva. 2020. Minority Language Families in Diaspora: Language Transmission among Catalans and Galicians in New York City. Submitted.

Kasuya, Hiroko. 1998. Determinants of language choice in bilingual children: The role of input. The International Journal of Bilingualism 2: 327-46. [CrossRef]

Köppe, Regina. 1997. Sprachentrennung im Frühen Bilingualen Erstspracherwerb: Französisch, Deutsch. Tübingen: Narr.

Kozak, Karina, Ashley Greaves, Jane Waldfogel, Jyoti Angal, Amy J. Elliott, William P. Fifier, and Natalie Hiromi Brito. 2021. Paid maternal leave is associated with better language and socioemotional outcomes during toddlerhood. Infancy 26: 536-50. [CrossRef] [PubMed]

Lanza, Elizabeth. 2004. Language Mixing in Infant Bilingualism: A Sociolinguistic Perspective, 2nd ed. Oxford: Oxford University Press.

Müller, Natascha, and Tanja Kupisch. 2003. Zum simultanen Erwerb des Deutschen und des Französischen bei (un)ausgeglichen bilingualen Kindern. Vox Romanica 62: 145-69.

Müller, Natascha, Tanja Kupisch, Katrin Schmitz, and Katja Francesca Cantone. 2007. Einführung in die Mehrsprachigkeitsforschung. Tübingen: Narr. 
Patuto, Marisa, Malin Hager, Laia Arnaus Gil, Nadine Eichler, Veronika Jansen, Anika Schmeißer, and Natascha Müller. 2014. Childexternal and -internal factors in bilingual code-switching: Spanish, Italian, French and German. In Language Contact Around the Globe. Proceedings of the LCTG3 Conference. Edited by Amei Koll-Stobbe and Sebastian Knospe. Frankfurt am Main: Lang, pp. 191-209.

Pearson, Barbara, Sylvia Fernández, Vanessa Lewedeg, and D. Kimbrough Oller. 1997. The relation of input factors to lexical learning by bilingual infants. Applied Psycholinguist 18: 41-58. [CrossRef]

PEGV, Portal Estadístic de la Generalitat Valenciana. 2020. Govern de la Generalitat Valenciana. Available online: http:/ / www.pegv. gva.es/va/ (accessed on 11 December 2020).

Peix, Rita. 2013. Orígens, llengües i motivacions dels pares d'alumnes de l'ensenyament en català a la Catalunya del Nord. Treballs de Sociolingüística Catalana 23: 391-406.

Quay, Suzanne. 2001. Managing linguistic boundaries in early trilingual development. In Trends in Bilingual Acquisition. Edited by J. Cenoz and F. Genesee. Philadelphia: Benjamins, pp. 149-99.

Romaine, Suzanne. 1995. Bilingualism, 2nd ed. Oxford: Blackwell.

Ronjat, Jules. 1913. Le Development du Langage Observe Chez un Enfant Bilingue. Paris: Champion.

Rowe, M. L. 2012. A longitudinal investigation of the role of quantity and quality of child-directed speech in vocabulary development. Child Development 8: 1762-74. [CrossRef] [PubMed]

Schmeißer, Anika, Malin Hager, Laia Arnaus Gil, Veronika Jansen, Jasmin Geveler, Nadine Eichler, Marisa Patuto, and Natascha Müller. 2016. Related but different: The two concepts of language dominance and language proficiency. In Language Dominance in Bilinguals: Issues of operationalisation and measurement. Edited by Carmen Silva-Corvalán and Jeanine Treffers-Daller. Cambridge: Cambridge University Press, pp. 36-65.

Schmitz, Katrin, and Anna-Lena Scherger. 2017. Effects of age and education on variable but native heritage grammars: Theoretical and empirical implications for the Null Subject Parameter. Applied Linguistics Review 10: 443-67. [CrossRef]

Thordardottir, Elin. 2015. The relationship between bilingual exposure and morphosyntactic development. International Journal of Speech Language Pathology 17: 97-114. [CrossRef]

Torregrossa, Jacobo, and Christiane Bongartz. 2018. Teasing apart the effects of dominance, transfer and processing in reference production by German-Italian bilingual adolescents. Languages 3: 36. [CrossRef]

Unsworth, S. 2013. Assessing the role of current and cumulative exposure in simultaneous bilingual acquisition: The case of Dutch gender. Bilingualism: Language and Cognition 16: 86-110. [CrossRef]

Yip, Virginia, and Stephen Matthews. 2000. Syntactic transfer in a Cantonese-English bilingual child. Bilingualism: Language and Cognition 3: 193-207. [CrossRef]

Yip, Virginia, and Stephen Matthews. 2006. Assessing Language Dominance in Bilingual Acquisition: A Case for Mean Length Utterance Differentials. Language Assessment Quarterly 3: 97-116. [CrossRef] 